Brazilian Journal

of Chemical

Engineering

\title{
CAROTENOID-PRODUCING YEASTS IN THE BRAZILIAN BIODIVERSITY: ISOLATION, IDENTIFICATION AND CULTIVATION IN AGROINDUSTRIAL WASTE
}

\author{
Deborah M. Otero ${ }^{1 *}$, Bruna A. Bulsing ${ }^{1}$, Katira da M. Huerta ${ }^{1}$, Carlos A. Rosa ${ }^{2}$, \\ Rui C. Zambiazi ${ }^{3}$, Carlos A. V. Burkert ${ }^{1}$ and Janaína F. de M. Burkert ${ }^{1}$ \\ ${ }^{1}$ Universidade Federal do Rio Grande, Escola de Química e Alimentos, Laboratório de Engenharia de Bioprocessos, Rio Grande/RS, \\ Brasil. E-mail: deborah.m.otero@gmail.com, ORCID: 0000-0001-9792-3992 \\ ${ }^{2}$ Universidade Federal de Minas Gerais, Instituto de Ciências Biológicas, Laboratório de Microbiologia, Belo Horizonte/MG, Brasil. \\ ${ }^{3}$ Universidade Federal de Pelotas, Departamento de Ciência e Tecnologia de Alimentos, Laboratório de Cromatografia, Pelotas/RS, Brasil.
}

(Submitted: August 21, 2017 ; Revised: July 25, 2018 ; Accepted: August 4, 2018)

\begin{abstract}
Different yeast strains from forests located in southern Brazil, with potential to produce carotenoids, were isolated. Three microorganisms were selected as potential carotenoid producers. Sporiodiobolus pararoseus, Rhodotorula mucilaginosa and Pichia fermentans were grown in Yeast Malt (YM) medium and the carotenoids produced identified as cryptoxanthin and $\beta$-carotene. In order to reduce production costs, agroindustrial residues were used in the formulation of medium A (parboiled rice water and crude glycerol) and medium B (parboiled rice water and sugar cane molasses). The highest carotenoid production was obtained with S. pararoseus. It reached $905.30 \mu \mathrm{gL}^{-1}\left(122.82 \mu \mathrm{g} \mathrm{g}^{-1}\right)$ in YM medium, $820 \mu \mathrm{g} \mathrm{L}^{-1}\left(68.04 \mu \mathrm{g} \mathrm{g}^{-1}\right)$ in medium $\mathrm{B}$ and $710 \mu \mathrm{g} \mathrm{L}^{-1}\left(86.46 \mu \mathrm{g} \mathrm{g}^{-1}\right)$ in medium A. R. mucilaginosa exhibited the best performance in medium B (360 $\mu \mathrm{g} \mathrm{L}^{-1}$ and $30.16 \mu \mathrm{g} \mathrm{g}^{-1}$ ) and a new microorganism - P. fermentans - reached $48 \%$ (medium A) and $78 \%$ (medium B) of the value found in YM medium. Therefore, the agroindustrial residues under evaluation, which replaced the commonly used nitrogen and carbon sources in culture media, enabled the isolated yeasts to yield carotenoids.

Keywords: Agroindustrial byproducts; $\beta$-carotene; Yeast screening; Natural pigments.
\end{abstract}

\section{INTRODUCTION}

Carotenoids, which are the most widespread class of pigments in nature, are usually tetraterpenoids with 40 carbon atoms. These molecules have a system of double bonds that constitute the chromophore group responsible for the colors - red, orange and yellow - they exhibit. Widely found in plants, animals and microorganisms (Maldonade et al., 2008) and applied in food, pharmaceutical, cosmetic and feed industries (Zeni et al., 2011), they have higher economic and technological value than other microbial pigments (Tuli et al., 2015).
Importance has recently been given to carotenoids in the scientific field, not only due to their wide use as pigment in foods and precursors of vitamin A, but also because of their beneficial effects on human health. Some carotenoids, such as $\beta$-carotene and $\beta$-cryptoxanthin, have been highlighted due to their antioxidant action and protection against cardiovascular diseases and some types of cancer (Rao and Rao, 2007), besides the fact that they inhibit lipoprotein oxidation processes. Moreover, zeaxanthin exerts protective action against macular degeneration and cataracts (Ma and Lin, 2010), strengthens the

\footnotetext{
* Corresponding author: Deborah M. Otero - E-mail: deborah.m.otero@gmail.com
} 
immune system (Fusco et al., 2007) and has antiinflammatory and anticarcinogenic activity (Preetha et al., 2008).

Habits of health-conscious people and their concern for the use of chemical additives in food have intensified researches on carotenoid production by biotechnological processes with algae such as Dunaliella salina, Tetraselmis suecica, Isochrysis galbana, Pavlova salina (Ahmed et al., 2014) and Haematococcus pluvialis (Machado Jr. et al., 2016); bacteria such as Rhodopseudomonas palustris (Kuo et al., 2012), Halobacterium salinarum, Halorubrum sodomense, Haloarcula valismortis and Salinibacter ruber (Jehlička et al., 2013); and yeasts such as Phaffia rhodozyma and Xanthophyllomyces dendrorhous (Pollmann et al., 2017; Silva et al., 2016; Cipolatti et al., 2015; Rios et al., 2015), Rhodotorula mucilaginosa (Manimala and Murugesan, 2017; Maldonade et al. 2012) and Sporidiobolus pararoseus (Machado and Burkert, 2015; Wei et al., 2014; Manowattana et al., 2018). Carotenoids, such as trans-violaxanthin, antheraxanthin, astaxanthin, lutein epoxide, lutein, zeaxanthin, $\alpha$ - and $\beta$-carotene were produced by algae (Ahmed et al., 2014). Bacterioruberin and salinixanthin were obtained with bacteria (Jehlička et al., 2013), while yeasts synthesized carotenoids such as $\beta$-carotene, lutein, torulene, torularhodin and astaxanthin (Cipolatti et al., 2015; Wei et al., 2014). Other multi-oxygenated carotenoids were produced by genetically modified microorganisms (Pollmann et al., 2017).

Yeasts are notable for their growth capacity and production using different agroindustrial wastes as substrate. Phaffia rhodozyma, with the use of crude glycerol, a byproduct of biodiesel production, and parboiled rice water (Silva et al., 2012), reached $1,700 \mu \mathrm{g} \mathrm{L}^{-1}\left(275.5 \mu \mathrm{g} \mathrm{g}^{-1}\right)$. With the same yeast, the optimization of the culture medium with parboiled rice water led to a production of $5,300 \mu \mathrm{g} \mathrm{L}^{-1}(628.8$ $\mu \mathrm{g} \mathrm{g}^{-1}$ ) (Rios et al., 2015). Banzatto et al. (2013), in the cultivation of $R$. rubra, reached $274 \mu \mathrm{g} \mathrm{L}^{-1}$ (33 $\mu \mathrm{g} \mathrm{g}^{-1}$ ) with sugar cane juice, sugar cane molasses and syrup and produced torulene, torularhodin and $\beta$-carotene. $S$. pararoseus, with corn steep liquor and sugar cane molasses, reached a production of 521 $\mu \mathrm{g} \mathrm{L}^{-1}\left(73 \mu \mathrm{g} \mathrm{g}^{-1}\right)$, while the use of corn steep liquor and crude glycerol led to a production of $780 \mu \mathrm{g} \mathrm{L}^{-1}$ (66 $\mu \mathrm{g} \mathrm{g}^{-1}$ ) (Machado and Burkert, 2015). Thus, they are promising alternatives for carotenoid industrial bioproduction, since they minimize costs of the cultivation medium and add value to the agroindustrial waste used as substrate.

Brazil has the greatest biodiversity on the planet, even though its microbiota is still largely unknown. Yeasts represent a part of the microflora of natural ecosystems, which may be desirable sources of various compounds, such as carotenoids. However, isolation and selection of potential carotenoid-producing yeasts have been poorly explored in Brazil (Zeni et al., 2011; Maldonade et al., 2008).

Therefore, the main goal of this study was the isolation, selection and identification of new yeast strains from forests located in southern Brazil as potential carotenoid producers. Besides, the potential of agroindustrial waste as substrate for the production of high value-added bioproducts was also evaluated.

\section{MATERIAL AND METHODS}

\section{Pigmented yeast screening}

For yeast isolation, samples of soil, bark, flowers, leaves and fruits were collected in different regions (the Sul-Riograndense Shield and the Eastern Coast) in southern Brazil. These samples were aseptically packaged. Strains that showed coloration were isolated and codified to facilitate further identification. Identified yeasts were then deposited in the André Toselo Tropical Culture Collection (Campinas, Brazil).

\section{Yeast isolation and selection}

Samples were placed in Erlenmeyer flasks with 20 $\mathrm{mL}$ YM broth $(0.3 \%$ yeast extract, $0.3 \%$ malt extract, $0.5 \%$ peptone and $1.0 \%$ glucose) and incubated at $30^{\circ} \mathrm{C}$ for $48 \mathrm{~h}$. They were then inoculated in Petri dishes with YM agar and incubated at $30^{\circ} \mathrm{C}$ for $120 \mathrm{~h}$. Yellow to red colonies were transferred to slant tubes with YM agar and incubated at $30^{\circ} \mathrm{C}$ until satisfactory growth. These colored cultures were re-isolated in Petri dishes with YM agar (incubated at $30^{\circ} \mathrm{C}$ for 72 h), transferred to slant tubes with GYMP agar $(2.0 \%$ glucose, $0.5 \%$ yeast extract, $0.3 \%$ malt, $0.5 \%$ peptone, $0.2 \%$ monobasic sodium phosphate and $2.0 \%$ agar) and stored at $4^{\circ} \mathrm{C}$ after having grown (Maldonade et al., 2007).

\section{Shake flask cultivation in YM medium}

For yeast selection, an inoculum was prepared in $250 \mathrm{~mL}$ Erlenmeyer flasks with $100 \mathrm{~mL}$ YM medium at initial $\mathrm{pH} 6.0$, previously sterilized at $121^{\circ} \mathrm{C}$ for 15 min. Flasks were inoculated with a loopful of suspended cells from the slant tubes and incubated at $25^{\circ} \mathrm{C}$ and $180 \mathrm{rpm}$ for $48 \mathrm{~h}$.

Cultures for carotenoid bioproduction were prepared in triplicate in $500 \mathrm{~mL}$ Erlenmeyer flasks with $250 \mathrm{~mL}$ culture medium at initial $\mathrm{pH}$ 6.0. Ten percent inoculum was added to each flask (to reach an initial cell concentration of $1 \times 10^{7}$ cells $\left.\mathrm{mL}^{-1}\right)$, then they were disposed in an orbital shaker (Tecnal model TE 424, Brazil) at $25^{\circ} \mathrm{C}$ and $180 \mathrm{rpm}$ without light for $168 \mathrm{~h}$ (Michelon et al., 2012). At this time, biomass concentration and total carotenoids were determined. 


\section{Yeast identification}

Selected yeasts were characterized by PCR fingerprinting, i.e., the $\mathrm{mini} /$ microsatellite-primed PCR technique (MSP-PCR) (Libkind et al., 2003).

\section{DNA extraction}

For DNA extraction, yeast colonies were grown on modified Sabouraud agar $(2 \%$ glucose, $1 \%$ peptone, $0.5 \%$ yeast extract and $2 \%$ agar) at $25^{\circ} \mathrm{C}$ overnight, transferred to $2 \mathrm{~mL}$ sterile tubes (Eppendorf) with $100 \mathrm{~mL}$ extraction buffer solution (50 mmol Tris, 250 mmol NaCl, 50 mmol EDTA, 0.3\% $\mathrm{wv}^{-1} \mathrm{SDS}, \mathrm{pH} 8$ ) and incubated at $65^{\circ} \mathrm{C}$ for $30 \mathrm{~min}$. After incubation, $100 \mathrm{~mL}$ phenol/chloroform/isoamyl alcohol (25:24:1) was added. The mixture was vigorously vortexed, incubated for $3 \mathrm{~min}$ and centrifuged at $7558 \mathrm{x} \mathrm{g}$ for 3 min. DNA was dried at room temperature overnight, suspended in $100 \mathrm{~mL}$ TE buffer $(10 \mathrm{mM}$ Tris, $10 \mathrm{mM}$ Na-EDTA, pH 8.0) and stored in a refrigerator.

\section{PCR fingerprinting}

Synthetic oligonucleotide (GTG) 5 and the core sequence of phage M13 (GAGGGTGGCGGTTCT) were used in MSP-PCR experiments, respectively. PCR reactions were performed in agreement with Libkind et al. (2003). Twenty yeast strains with identical DNA banding patterns were grouped and putatively considered to belong to the same species (Gadanho and Sampaio, 2002). At least one representative strain of each MSP-PCR group was subjected to the sequence analysis of D1/D2 domains of the large subunit of the rRNA gene, as described below. Physiologically distinct strains with unique MSP-PCR banding patterns were also selected for direct identification by sequencing the D1/D2 region of the rRNA gene. Whenever necessary, internal transcribed spacer (ITS) domains of the rRNA gene were also sequenced.

\section{Sequence analysis}

Total DNA was extracted and the D1/D2 variable domains of the large subunit of the rRNA gene were amplified (Lachance et al., 1999) with primers NL-1 (50-GCATATCAATAAGCGGAGGAAAAG-30) and NL-4 (50-GGTCCGTGTTTCAAGACGG-30). ITS regions of rRNA genes were amplified with universal primers ITS1 (50-TCCGTAGGTGAACCTGCGG-30) and ITS4 (50-TCCTCCGCTTATTGATATGC-30) (White et al., 1990). Primers used by this study have high accuracy for yeast identification and have also been used by most researches on yeast taxonomy (Kurtzman et al., 2011)

Sequencing of the D1/D2 region and ITS domains was directly performed with purified PCR products by a MegaBaceTM 1000 automated sequencing system (Amersham Biosciences, USA). Sequences were compared with those found in the GenBank database by the BASIC LOCAL ALIGNMENT SEARCH TOOL (BLAST at http://www.ncbi.nlm.nih. gov). In general, strains of a species show no more than 0 to 3 nucleotide differences $(0-0.5 \%$ identity) in D1/D2 domains, while strains that show 6 or more noncontiguous substitutions ( $1 \%$ identity) are separate species (Kurtzman and Robnett, 1998). According to Daniel et al. (2009), the most commonly detected intraspecific sequence variability is $0-4$ differences in the ITS region. Species with more nucleotide differences are not considered generally conspecific.

\section{Shake flask cultivation in agroindustrial medium Agroindustrial waste}

Crude glycerol $\left(83.08 \% \mathrm{w} \mathrm{w}^{-1}\right.$ glycerol) derived from the synthesis of biodiesel, sugar cane molasses and parboiled rice water were kindly provided by industries located in the south of Brazil. Parboiled rice water was maintained under refrigeration $\left(4 \pm 2^{\circ} \mathrm{C}\right)$ and centrifuged at $1,745 \mathrm{x} \mathrm{g}$ for $10 \mathrm{~min}$ in order to enable particle removal before use.

\section{Partial characterization of substrates}

Partial characterization of substrates of the culture media (yeast extract, malt extract, peptone, parboiled rice water, sugar cane molasses and crude glycerol) was performed by determining carbon, nitrogen and hydrogen concentrations by a CHNS/O analyzer (Perkin Elmer, 2400, Germany). For equipment calibration, acetanilide was used as the certified reference material.

Except for carbon determinations in sugar cane molasses, a total organic carbon analyzer (TOC-V CPH / CPN, Shimadzu, Japan) was used with the NPOC (non-purgeable organic carbon) method. Nitrogen concentrations of parboiled rice water and sugar cane molasses were determined by Micro Kjeldahl (AOAC, 2000).

\section{Shake flask cultivation}

A similar procedure to the one described aboce for YM medium was used, but the volume of the culture medium was adjusted to $306 \mathrm{~mL}$.

In order to obtain the same Carbon/Nitrogen $(\mathrm{C} / \mathrm{N})$ ratio found in YM medium (6.20), the Solver tool (Excel 2010 software, Microsoft Inc., USA) was used for calculating component concentrations by linear programming, considering both nitrogen and carbon contents of agroindustrial waste. Culture media for carotenoid production (C/N ratio of 6.20) were: medium A, which consisted of parboiled rice water (39.91 $\left.\mathrm{g} \mathrm{L}^{-1}\right)$ and crude glycerol $\left(17.31 \mathrm{~g} \mathrm{~L}^{-1}\right)$; medium $\mathrm{B}$, which was composed of parboiled rice water (44.01 $\left.\mathrm{g} \mathrm{L}^{-1}\right)$ and sugar cane molasses $\left(23.6 \mathrm{~g} \mathrm{~L}^{-1}\right)$; and $\mathrm{YM}$ medium ( $3 \mathrm{~g} \mathrm{~L}^{-1}$ malt extract, $3 \mathrm{~g} \mathrm{~L}^{-1}$ yeast extract, $5 \mathrm{~g}$ $\mathrm{L}^{-1}$ peptone, $10 \mathrm{~g} \mathrm{~L}^{-1}$ glucose). 


\section{Analytical methods}

\section{Total carotenoid determination}

For total carotenoid recovery, samples were centrifuged at $1800 \mathrm{xg}$ at $25^{\circ} \mathrm{C}$ for $10 \mathrm{~min}$ to separate biomass, which was submitted to drying (at $35^{\circ} \mathrm{C}$ for $48 \mathrm{~h}$ ) and successive maceration in a mortar with a pestle. Then, it was frozen (at $-18^{\circ} \mathrm{C}$ for $48 \mathrm{~h}$ ). Afterwards, $0.05 \mathrm{~g}$ cell was added to $2 \mathrm{~mL}$ DMSO (dimethylsulphoxide) (Nuclear, Brazil), previously heated at $55^{\circ} \mathrm{C}$ (Fanem 102, Brazil) for $1 \mathrm{~h}$, with periodic vortex homogenization (Biomixer, QL-901, Brazil). In agreement with Fonseca et al. (2011), $6 \mathrm{~mL}$ of acetone (Quimex, Brazil) was then added, followed by centrifugation at $1800 \times \mathrm{g}$ at $25^{\circ} \mathrm{C}$ for $10 \mathrm{~min}$. The supernatant was separated and successive extractions were carried out until cells were colorless. Ten $\mathrm{mL}$ of $20 \% \mathrm{NaCl}\left(\mathrm{w} \mathrm{v}^{-1}\right)$ solution and $10 \mathrm{~mL}$ of petroleum ether were added. After stirring and phase separation, the excess of water was removed with $\mathrm{Na}_{2} \mathrm{SO}_{4}$ in order to obtain carotenogenic extracts (Rodriguez-Amaya et al., 2008).

Total carotenoid concentration was determined by spectrophotometric (Biospectro, SP 220, China) reading at $474 \mathrm{~nm}$ (Rodriguez-Amaya et al., 2008). Values were obtained by Eq.1 with the specific absorptivity coefficient in petroleum ether, i. e., $2100 \mathrm{~mol} \mathrm{~L}^{-1} \mathrm{~cm}^{-1}$ (Domínguez-Bocanegra and TorresMunoz, 2004).

$\mathrm{SPC}=\frac{100 \mathrm{~A}_{474} \mathrm{~V}}{21 \mathrm{~m}}$

where SPC is the specific total carotenoid concentration $\left(\mu \mathrm{g} \cdot \mathrm{g}^{-1}\right), \mathrm{A}_{474}$ is the absorbance at $474 \mathrm{~nm}, \mathrm{~V}$ is the filtrate volume $(\mathrm{mL})$, and $\mathrm{m}$ is the dry cell mass $(\mathrm{g})$.

To calculate the volumetric concentration of total carotenoids (VPC) $\left(\mu \mathrm{g} \mathrm{L}^{-1}\right)$, both total carotenoid concentration $\left(\mu \mathrm{g} \mathrm{g}^{-1}\right)$ and biomass concentration $(\mathrm{g}$ $\mathrm{L}^{-1}$ ) were used. Units were converted.

\section{Carotenoid identification}

Identification of carotenoids produced with YM medium (168h) was carried out by extract concentration in a rotary evaporator (Fisaton model 802, Brazil) and re-dissolution in $5 \mathrm{~mL}$ methanol:acetonitrile 30:70 (v:v). A $20 \mu \mathrm{L}$ aliquot was then injected into the liquid chromatography. An HPLC system (Shimadzu, Japan), consisting of an automatic sampler (SIL-10AF), a solvent mixing module (LC-10 ALvp), an automatic degasser (FCV-10ALvp), a quaternary pump (DGU14A), a column oven compartment (CTO-10ASvp) set at $25^{\circ} \mathrm{C}$, a UV-Vis spectrophotometric detector (SPD10Avp) set at $450 \mathrm{~nm}$ and a control system (SCL10avp), were used. A Shim-Pak reverse phase CLCODS column $(4.6 \mathrm{~cm}$ x $150 \mathrm{~mm}$ x $5 \mu \mathrm{m}$ particle size, Shimadzu) with an octadecyl stationary phase and a guard column CLC- GODS (5 $\mu \mathrm{m}, 2 \mathrm{~cm} \mathrm{x} 4 \mathrm{~mm}$, Supelco) were also used.

Elution was carried out at flow rate of $1 \mathrm{mLmin}^{-1}$ with an initial mobile phase of $30 \%$ methanol (A), $70 \%$ acetonitrile (B) and $0 \%$ acetyl acetate (C) for 10 min. Percentages remained 10\% (A), 80\% (B) and $10 \%$ (C) up to $35 \mathrm{~min}$. Afterwards, they were $5 \%$ (A), $80 \%$ (B) and $15 \%$ (C) up to $40 \mathrm{~min}$. Finally, the initial mobile phase was maintained up to $45 \mathrm{~min}$, and then kept for 3 min (Marinova and Ribarova, 2007).

Carotenoids were identified by comparing their retention times, with the help of a calibration curve obtained with the following standards: $\beta$-carotene, which was provided by Fluka (Saint Louis, USA) and $\beta$ - cryptoxanthin, zeaxanthin and lycopene, which were supplied by Chromadex (Irvine, CA, USA). All had $97 \%$ purity.

\section{Biomass determination}

For yeast selection, a $10 \mathrm{~mL}$ sample was centrifuged at $1800 \times \mathrm{g}$ and $25^{\circ} \mathrm{C}$ for $10 \mathrm{~min}$. Then, cells were washed with distilled water and centrifuged again. Cell mass was quantified by drying at $105^{\circ} \mathrm{C}$ until constant weight (AOAC, 2000). In the case of the selected yeasts, biomass concentration was estimated by absorbance reading at $620 \mathrm{~nm}$ and the value was converted to $\mathrm{g} \mathrm{L}^{-1}$ with the use of a previously constructed standard curve (Kusdyantini et al., 1998).

\section{pH determination}

$\mathrm{pH}$ was determined by a potentiometer (Marte, MB-10, Brazil), in agreement with the AOAC (2000).

\section{Determination of total reducing sugar concentration}

Total reducing sugar (TRS) concentrations were determined in cell free supernatant previously centrifuged at $3439 \mathrm{x} \mathrm{g}$ for $10 \mathrm{~min}$ for YM medium and $\mathrm{B}$ medium (parboiled rice water and sugar cane molasses). One $\mathrm{mL}$ culture medium with the agroindustrial byproducts was submitted to hydrolysis with $2 \mathrm{~mL}$ of $2.0 \mathrm{moL} \mathrm{L}^{-1} \mathrm{HCl}$ in a water bath at $55^{\circ} \mathrm{C}$ for $30 \mathrm{~min}$, followed by the addition of $2 \mathrm{~mL}$ of $2.0 \mathrm{~mol} \mathrm{~L}^{-1} \mathrm{NaOH}$ for acid neutralization (Liu et al., 2012). Subsequently, TRS was determined by the spectrophotometric method of 3,5-dinitrosalicylic (DNS), in accordance with Miller (1959), with the use of a standard glucose curve (between 0.1 and $1.0 \mathrm{~g}$ $\left.\mathrm{L}^{-1}\right)$.

\section{Kinetic parameters of cultivation}

The substrate-to-product conversion factor $\left(\mathrm{Y}_{\mathrm{P} / \mathrm{S}}\right.$, microgram carotenoids per gram glucose), the substrate-to-biomass conversion factor $\left(\mathrm{Y}_{\mathrm{X} / \mathrm{S}}\right.$, gram cells per gram substrate) and the biomass to product conversion factor $\left(\mathrm{Y}_{\mathrm{P} / \mathrm{X}}\right.$, microgram carotenoids per gram cells) were calculated (Bailey and Ollis, 1986). 
Cell productivity $\left(\mathrm{P}_{\mathrm{x}}, \mathrm{g} \mathrm{L}^{-1} \mathrm{~h}^{-1}\right)$ and total carotenoid productivity $\left(\mathrm{P}_{c} \mu \mathrm{g} \mathrm{g}^{-1} \mathrm{~h}^{-1}\right)$ were determined by cell growth curves and carotenoid production (Bailey and Ollis, 1986).

Maximum specific growth rate $\left(\mu_{\text {max }}\right)$ was calculated by Eq. 2, by using the Microcal Origin ${ }^{\circledR} 5.0$ software.

$\mu_{\max }=\frac{1}{\mathrm{X}} \frac{\mathrm{dX}}{\mathrm{dt}}$

where $\mu_{\text {máx }}$ is the maximum specific growth rate $\left(\mathrm{h}^{-1}\right)$ and $\mathrm{X}$ is the biomass concentration $\left(\mathrm{g} \mathrm{L}^{-1}\right)$.

\section{Statistical analysis}

All experiments were performed in triplicate $(n=3)$ and results were treated by the analysis of variance followed by the Tukey's post-hoc test $(\mathrm{p}<0.05)$, using Statistica 5.0 software (StatSoft Inc., USA).

\section{RESULTS AND DISCUSSION}

\section{Yeast diversity}

In this study, 147 environmental samples were collected in two ecosystems: 42, in flowers; 19 , in

Table 1. Biomass $\left(\mathrm{g} \mathrm{L}^{-1}\right)$ and total carotenoids $\left(\mu \mathrm{g} \mathrm{L}^{-1}\right.$ or $\mu \mathrm{g} \mathrm{g}^{-1}$ ) of yellow yeasts.

\begin{tabular}{|c|c|c|c|}
\hline \multirow{2}{*}{ Code } & \multirow{2}{*}{$\begin{array}{c}\text { Biomass } \\
\left(\mathrm{g} \mathrm{L}^{-1}\right)\end{array}$} & \multicolumn{2}{|c|}{ Carotenoids } \\
\hline & & $\left(\mu g g^{-1}\right)$ & $\left(\mu g \mathrm{~L}^{-1}\right)$ \\
\hline A1 & $7.43 \pm 0.15^{\mathrm{g}, \mathrm{h}, \mathrm{i}, \mathrm{j}}$ & $17.52 \pm 2.96^{\mathrm{d}}$ & $140 \pm 37.40^{d}$ \\
\hline $\mathrm{A} 2$ & $1.28 \pm 0.24^{\mathrm{n}, \mathrm{o}}$ & $2.76 \pm 0.27^{\mathrm{k}, 1 . \mathrm{m}, \mathrm{n}}$ & $3.53 \pm 08^{j}$ \\
\hline A10 & $7.00 \pm 0.10^{\mathrm{i}, \mathrm{j}, \mathrm{k}}$ & $2.67 \pm 0.33^{1, \mathrm{~m}, \mathrm{n}}$ & $18.33 \pm 2.05^{h, i, j}$ \\
\hline A 12 & $9.00 \pm 0.10^{\mathrm{d}, \mathrm{e}, \mathrm{f}, \mathrm{g}, \mathrm{h}}$ & $4.60 \pm 0.15^{\mathrm{h}, \mathrm{i}, \mathrm{j}, \mathrm{k}, \mathrm{l}, \mathrm{m}}$ & $40.00 \pm 1.25^{\mathrm{f}, \mathrm{g}, \mathrm{h}, \mathrm{i}, \mathrm{j}}$ \\
\hline A14 & $7.13 \pm 0.86^{\mathrm{h}, \mathrm{i}, \mathrm{j}, \mathrm{k}}$ & $2.88 \pm 0.11^{\mathrm{k}, \mathrm{l}, \mathrm{m}, \mathrm{n}}$ & $20.33 \pm 2.49^{\mathrm{h}, \mathrm{i}, \mathrm{j}}$ \\
\hline A15 & $8.37 \pm 0.83^{\mathrm{f}, \mathrm{g}, \mathrm{h}, \mathrm{i}, \mathrm{j}}$ & $3.52 \pm 0.30^{\mathrm{j}, \mathrm{k}, 1, \mathrm{~m}, \mathrm{n}}$ & $29.00 \pm 2.16^{\mathrm{g}, \mathrm{hi}, \mathrm{j}}$ \\
\hline A16 & $4.46 \pm 0.217^{1, \mathrm{~m}}$ & $6.37 \pm 0.08^{\mathrm{g}, \mathrm{h}, \mathrm{i}, \mathrm{j}, \mathrm{k}, \mathrm{l}, \mathrm{l}}$ & $20.00 \pm 1.411^{\mathrm{g}, \mathrm{g}, \mathrm{i}, \mathrm{j}}$ \\
\hline A20 & $11.67 \pm 1$ & $11.15 \pm 0.15^{\mathrm{e}, \mathrm{f}}$ & $126.67 \pm 12.47^{\mathrm{d}}$ \\
\hline A21 & $8.57 \pm$ & $16.02 \pm 0.02^{e, f}$ & $133.33 \pm 17^{\mathrm{d}}$ \\
\hline A23 & $7.13 \pm 0$ & $7.26 \pm 0.06^{\mathrm{f}, \mathrm{g}, \mathrm{h}, \mathrm{i}, \mathrm{j}}$ & $20.33 \pm 2.49^{\mathrm{f}, \mathrm{g}, \mathrm{h}, \mathrm{i}, \mathrm{j}}$ \\
\hline A24 & $8.10 \pm 0$. & $14.31 \pm 0.27^{\mathrm{d}, \mathrm{e}}$ & $113.33 \pm 4.71^{\mathrm{d}, \mathrm{e}}$ \\
\hline A27 & $2.27 \pm$ & $10.19 \pm 0.12^{\mathrm{f}, \mathrm{g}}$ & $19.67 \pm 0.47^{\text {h,i,j }}$ \\
\hline A28 & $9.20 \pm 0$ & $6.74 \pm 0.12^{\mathrm{g}, \mathrm{h}, \mathrm{i}, \mathrm{j}, \mathrm{k}}$ & $61.6 \pm 3.30^{\mathrm{f}, \mathrm{g}, \mathrm{h}, \mathrm{i}}$ \\
\hline $\mathrm{B} 2$ & $10.80 \pm 0.61^{\mathrm{a},}$ & $8.47 \pm 1.11^{\mathrm{f}, \mathrm{g}, \mathrm{h}}$ & $88.33 \pm 8.50^{\mathrm{d}, \mathrm{e}, \mathrm{f}}$ \\
\hline B7 & $8.07 \pm 0.40^{f, g}$, & $0.00 \pm<0.01^{\mathrm{n}}$ & $0.00 \pm<0.01^{\mathrm{j}}$ \\
\hline B8 & $0.80=$ & $0.00 \pm<0.01^{\mathrm{n}}$ & $0.00 \pm<0.01^{\mathrm{j}}$ \\
\hline B9 & $9.53 \pm 0.2$ & $1.28 \pm 0.14^{\mathrm{m}, \mathrm{n}}$ & $11.67 \pm 0.94^{\mathrm{i}, \mathrm{j}}$ \\
\hline B10 & $9.07 \pm 0.21^{\mathrm{d}, \mathrm{e},}$ & $4.50 \pm 0.13^{\mathrm{h}, \mathrm{i}, \mathrm{j}, \mathrm{k}, \mathrm{l}, \mathrm{m}}$ & $3.70 \pm 0.6^{\mathrm{f}, \mathrm{g}, \mathrm{h}, \mathrm{i}, \mathrm{j}}$ \\
\hline B11 & $9.07 \pm 0.21^{\mathrm{d}, \mathrm{e}, \mathrm{f}, \mathrm{g}, \mathrm{h}}$ & $7.40 \pm 0.16^{\mathrm{f}, \mathrm{g}, \mathrm{h}, \mathrm{i}, \mathrm{j}}$ & $76.70 \pm 18.90^{\mathrm{e}, \mathrm{f}, \mathrm{g}, \mathrm{h}}$ \\
\hline B12 & $11.37 \pm 1.06^{\mathrm{a}, \mathrm{b}}$ & $34.29 \pm 0.17^{b}$ & $383.73 \pm 3.3^{b}$ \\
\hline B13 & $10.43 \pm 1.10^{\mathrm{a} b, \mathrm{c}, \mathrm{d}, \mathrm{e}}$ & $4.20 \pm 0.03^{\mathrm{i}, \mathrm{j}, \mathrm{k}, \mathrm{l}, \mathrm{m}}$ & $44.33 \pm 3.30^{\mathrm{f}, \mathrm{g}, \mathrm{h}, \mathrm{i}, \mathrm{j}}$ \\
\hline $\mathrm{C} 3$ & $11.07 \pm 0.63^{\mathrm{a}, \mathrm{b}, \mathrm{c}}$ & $24.56 \pm 1.89^{c}$ & $271.03 \pm 14.20^{c}$ \\
\hline C6 & $8.73 \pm 0.25^{\mathrm{e}, \mathrm{f}, \mathrm{g}, \mathrm{h}, \mathrm{i}}$ & $2.01 \pm 0.07^{\mathrm{m}, \mathrm{n}}$ & $17.50 \pm 0.22^{\mathrm{h}, \mathrm{i}, \mathrm{j}}$ \\
\hline $\mathrm{D} 2$ & $9.07 \pm 0.81^{\mathrm{d}, \mathrm{e}, \mathrm{f}, \mathrm{g}, \mathrm{h}}$ & $9.04 \pm 2.21^{\mathrm{f} g}$ & $66.70 \pm 2.49^{\mathrm{e}, \mathrm{f}, \mathrm{g}}$ \\
\hline D3 & $7.87 \pm 0.28^{f, g, h, i, j}$ & $122.82 \pm 5.27^{\mathrm{a}}$ & $905.30 \pm 41.35^{\mathrm{a}}$ \\
\hline D4 & $8.77 \pm 0.32^{\mathrm{e}, \mathrm{f}, \mathrm{g}, \mathrm{h}, \mathrm{i}}$ & $4.53 \pm 0.17^{\mathrm{h}, \mathrm{i}, \mathrm{j}, \mathrm{k}, \mathrm{l}, \mathrm{m}}$ & $38.67 \pm 0.47^{\mathrm{f}, \mathrm{g}, \mathrm{h}, \mathrm{i}, \mathrm{j}}$ \\
\hline D5 & $2.60 \pm 0.40^{\mathrm{m}, \mathrm{o}}$ & $7.63 \pm 0.38^{\mathrm{f}, \mathrm{g}, \mathrm{h}, \mathrm{i}}$ & $19.00 \pm 2.94^{\mathrm{h}, \mathrm{i}, \mathrm{j}}$ \\
\hline D6 & $.32 \pm 0.32^{\mathrm{k}, 1}$ & $1.35 \pm 0.09^{\mathrm{m}, \mathrm{n}}$ & $7.00 \pm<0.01^{\mathrm{j}}$ \\
\hline D7 & $2.96 \pm 0.09^{\mathrm{m}, \mathrm{n}}$ & $7.70 \pm 0.25^{\mathrm{f}, \mathrm{g}, \mathrm{h}, \mathrm{i}}$ & $22.67 \pm 0.94^{\mathrm{h}, \mathrm{i}, \mathrm{j}}$ \\
\hline D12 & $6.53 \pm 0.70^{\mathrm{j}, \mathrm{k}}$ & $7.54 \pm 0.10^{\mathrm{f,g}, \mathrm{h}, \mathrm{i}, \mathrm{j}}$ & $44.33 \pm 3.30^{\mathrm{f}, \mathrm{g}, \mathrm{h}, \mathrm{i}, \mathrm{j}}$ \\
\hline
\end{tabular}

Medium \pm standard deviation $(n=3)$. Different letters indicate significant difference among means in the same column $(\mathrm{p}<0.05)$. fruits; 35 , in bark; 14 , in the soil; and 37, in leaves. At the end, 683 yeast colonies were isolated. However, since only 64 yeasts had some coloration (30 yellow, 10 orange and 24 pink), they were selected and reisolated. Results are shown in Tables 1, 2 and 3.

Table 2. Biomass $\left(\mathrm{g} \mathrm{L}^{-1}\right)$ and total carotenoids $\left(\mu \mathrm{g} \mathrm{L}^{-1}\right.$ or $\mu \mathrm{g} \mathrm{g}^{-1}$ ) of orange yeasts.

\begin{tabular}{|c|c|c|c|}
\hline \multirow{2}{*}{ Code } & \multirow{2}{*}{$\begin{array}{c}\text { Biomass } \\
\left(\mathrm{g} \mathrm{L}^{-1}\right)\end{array}$} & \multicolumn{2}{|c|}{ Carotenoids } \\
\hline & & $\left(\mu \mathrm{g} \mathrm{g}^{-1}\right)$ & $\left(\mu \mathrm{g} \mathrm{L}^{-1}\right)$ \\
\hline A6 & $1.63 \pm 0.25^{b}$ & $2.62 \pm 0.33^{d}$ & $4.23 \pm 0.58^{\mathrm{d}}$ \\
\hline A9 & $3.90 \pm 0.20^{\mathrm{f}}$ & $3.85 \pm 0.73^{\mathrm{d}, \mathrm{e}}$ & $14.33 \pm 1.89^{\mathrm{d}}$ \\
\hline A13 & $3.81 \pm 0.31^{f}$ & $8.69 \pm 0.18^{c}$ & $33.66 \pm 0.89^{\mathrm{e}}$ \\
\hline A17 & $8.20 \pm 0.30^{\mathrm{e}}$ & $<0.01 \pm<0.01^{\mathrm{f}}$ & $1.00 \pm<0.01^{\mathrm{d}}$ \\
\hline A18 & $11.53 \pm 0.47^{c}$ & $5.00 \pm 0.10^{\mathrm{e}}$ & $57.33 \pm 0.94^{\mathrm{c}}$ \\
\hline A25 & $8.33 \pm 0.58^{\mathrm{e}}$ & $9.71 \pm 0.18^{c}$ & $78.67 \pm 0.94^{b}$ \\
\hline A26 & $9.83 \pm 0.45^{\mathrm{d}}$ & $4.40 \pm 0.15^{\mathrm{e}}$ & $42.67 \pm 2.36^{\mathrm{c}, \mathrm{c}}$ \\
\hline $\mathrm{B} 1$ & $11.23 \pm 0.06^{\mathrm{c}}$ & $25.33 \pm 1.60^{\mathrm{a}}$ & $280.00 \pm 14.1$ \\
\hline D1 & $9.40 \pm 0.53^{\mathrm{d}}$ & $3.70 \pm 0.30^{\mathrm{d}, \mathrm{e}}$ & $34.33 \pm 4.19^{e}$ \\
\hline D11 & $7.13 \pm 0.15^{\mathrm{a}}$ & $7.00 \pm 0.05^{b}$ & $46.67 \pm 4.71^{\mathrm{c},}$ \\
\hline
\end{tabular}

Medium \pm standard deviation $(n=3)$. Different letters indicate significant difference among means in the same column $(\mathrm{p}<0.05)$.

Table 3. Biomass $\left(\mathrm{g} \mathrm{L}^{-1}\right)$ and total carotenoids $\left(\mu \mathrm{g} \mathrm{L}^{-1}\right.$ or $\left.\mu \mathrm{g} \mathrm{g}^{-1}\right)$ of pink yeasts.

\begin{tabular}{|c|c|c|c|}
\hline \multirow{2}{*}{ Code } & \multirow{2}{*}{$\begin{array}{c}\text { Biomass } \\
\left(\mathrm{g} \mathrm{L}^{-1}\right)\end{array}$} & \multicolumn{2}{|c|}{ Carotenoids } \\
\hline & & $\left(\mu \mathrm{g} \mathrm{g}^{-1}\right)$ & $\left(\mu g \mathrm{~L}^{-1}\right)$ \\
\hline $\mathrm{A} 3$ & $1.27 \pm 0.21^{\mathrm{i}}$ & $4.13 \pm 0.60^{\mathrm{g}}$ & $5.17 \pm 0.65^{\mathrm{g}}$ \\
\hline A4 & $1.73 \pm 0.08^{\mathrm{i}}$ & $2.55 \pm 0.50^{\mathrm{g}, \mathrm{h}, \mathrm{i}}$ & $4.40 \pm 0.78^{\mathrm{g}, \mathrm{h}, \mathrm{i}}$ \\
\hline A5 & $1.78 \pm 0.19^{\mathrm{i}}$ & $26.55 \pm 1.75^{\mathrm{c}}$ & $46.67 \pm 4.11^{\mathrm{c}}$ \\
\hline A7 & $1.17 \pm 0.31^{\mathrm{i}}$ & $2.67 \pm 0.73 \mathrm{~g}, \mathrm{~h}, \mathrm{i}$ & $3.13 \pm 0.99^{\mathrm{g}, \mathrm{h}, \mathrm{i}}$ \\
\hline A8 & $0.55 \pm 0.15^{\mathrm{i}}$ & $<0.01 \pm<0.01^{\mathrm{i}}$ & $1.00 \pm<0.01^{\mathrm{i}}$ \\
\hline A11 & $6.63 \pm 0.18^{\mathrm{g}, \mathrm{h}}$ & $5.47 \pm 0.21^{\mathrm{f}, \mathrm{g}}$ & $35.67 \pm 1.89^{f, g}$ \\
\hline A19 & $11.97 \pm 0.25^{\mathrm{a}, \mathrm{b}}$ & $54.07 \pm 0.15^{\mathrm{a}}$ & $640.00 \pm 8.18^{a}$ \\
\hline A22 & $8.13 \pm 1.25^{\mathrm{d}, \mathrm{e}, \mathrm{f}, \mathrm{g}}$ & $13.26 \pm 0.13^{\mathrm{d}}$ & $103.00 \pm 9.43^{d}$ \\
\hline B3 & $2.41 \pm 0.30^{\mathrm{i}}$ & $3.23 \pm 1.80^{\mathrm{g}, \mathrm{h}, \mathrm{i}}$ & $7.57 \pm 3.59^{\mathrm{g}, \mathrm{h}, \mathrm{i}}$ \\
\hline B4 & $1.70 \pm 0.03^{\mathrm{i}}$ & $2.52 \pm 0.10^{\mathrm{g}, \mathrm{h}, \mathrm{i}}$ & $4.23 \pm 0.21^{\mathrm{g}, \mathrm{h}, \mathrm{i}}$ \\
\hline B5 & $1.36 \pm 0.26^{\mathrm{i}}$ & $42.27 \pm 3.16^{\mathrm{b}}$ & $57.67 \pm 11.81^{b}$ \\
\hline B14 & $10.67 \pm 0.73^{\mathrm{a}, \mathrm{b}, \mathrm{c}}$ & $10.03 \pm 0.05^{\mathrm{d}, \mathrm{e}}$ & $103.33 \pm 4.71^{\mathrm{d}, \mathrm{e}}$ \\
\hline $\mathrm{C} 1$ & $7.33 \pm 0.85^{\mathrm{f}, \mathrm{g}}$ & $<0.01 \pm<0.01^{\mathrm{i}}$ & $1.00 \pm<0.01^{\mathrm{g}, \mathrm{h}, \mathrm{i}}$ \\
\hline $\mathrm{C} 2$ & $6.30 \pm 1.08^{\mathrm{g}, \mathrm{h}}$ & $0.52 \pm 0.11^{\mathrm{h}, \mathrm{i}}$ & $3.47 \pm 0.97^{\mathrm{g}, \mathrm{h}, \mathrm{i}}$ \\
\hline $\mathrm{C} 4$ & $2.31 \pm 0.49^{\mathrm{i}}$ & $28.17 \pm 0.52^{\mathrm{f}, \mathrm{g}}$ & $12.33 \pm 4.01^{\mathrm{f}, \mathrm{g}}$ \\
\hline $\mathrm{C} 5$ & $9.97 \pm 1.51^{\mathrm{b}, \mathrm{c}, \mathrm{d}, \mathrm{e}}$ & $5.51 \pm 0.14^{\mathrm{f}, \mathrm{g}}$ & $54.33 \pm 6.34^{\mathrm{f}, \mathrm{g}}$ \\
\hline D8 & $8.30 \pm 1.24^{\text {d,e,f,g }}$ & $2.40 \pm 0.23 \mathrm{~g}, \mathrm{~h}, \mathrm{i}$ & $20.00 \pm 1.41^{\mathrm{g}, \mathrm{h}, \mathrm{i}}$ \\
\hline D9 & $12.67 \pm 060^{\mathrm{a}}$ & $2.32 \pm 0.06^{\mathrm{g}, \mathrm{h}, \mathrm{i}}$ & $26.33 \pm 4.50^{\mathrm{g}, \mathrm{h}, \mathrm{i}}$ \\
\hline D10 & $4.77 \pm 0.85^{\mathrm{h}}$ & $5.66 \pm 0.06^{\mathrm{f}, \mathrm{g}}$ & $23.33 \pm 4.71^{\mathrm{f}, \mathrm{g}}$ \\
\hline D13 & $7.57 \pm 1.12^{\mathrm{f}, \mathrm{g}}$ & $8.16 \pm 0.04^{\mathrm{e}, \mathrm{f}}$ & $60.67 \pm 7.04^{\mathrm{e}, \mathrm{f}}$ \\
\hline D14 & $1.53 \pm 0.15^{\mathrm{i}}$ & $3.60 \pm 0.08^{\mathrm{g}, \mathrm{h}}$ & $1.00 \pm<0.01^{\mathrm{g}, \mathrm{h}, \mathrm{i}}$ \\
\hline E1 & $9.07 \pm 1.00^{\mathrm{c}, \mathrm{d}, \mathrm{e}, \mathrm{f}}$ & $0.40 \pm 0.05^{h, i}$ & $3.70 \pm 0.6^{\mathrm{g}, \mathrm{h}, \mathrm{i}}$ \\
\hline E2 & $7.97 \pm 0.91^{\mathrm{e}, \mathrm{f}, \mathrm{g}}$ & $5.26 \pm 1.81^{\mathrm{g}}$ & $34.00 \pm 25.7^{\mathrm{g}}$ \\
\hline E3 & $10.33 \pm 0.55^{\mathrm{b}, \mathrm{c}, \mathrm{d}}$ & $9.88 \pm 1.11^{\mathrm{d}, \mathrm{e}}$ & $378.30 \pm 39.1^{\mathrm{d}, \mathrm{e}}$ \\
\hline
\end{tabular}

Medium \pm standard deviation $(n=3)$. Different letters indicate significant difference among means in the same column $(\mathrm{p}<0.05)$.

\section{Yeast screening for carotenoid production}

Isolated yeasts were grown to determine biomass and total carotenoid concentration (168 h cultivation). In this growth period, a statistical evaluation $(p<0.05)$ was carried out to select the most promising yeasts for yellow, orange and pink carotenoid production.

Strains D3, B12 and C3 produced yellow carotenoids: $905.30 \mu \mathrm{g} \mathrm{L}^{-1}\left(122.82 \mu \mathrm{g} \mathrm{g}^{-1}\right)$ with 7.87 
$\mathrm{g} \mathrm{L}^{-1}$ biomass, $383.73 \mu \mathrm{g} \mathrm{L}^{-1}\left(34.29 \mu \mathrm{g} \mathrm{g}^{-1}\right)$ with 11.37 $\mathrm{g} \mathrm{L}^{-1}$ and $271.03 \mu \mathrm{g} \mathrm{L}^{-1}\left(24.56 \mu \mathrm{g} \mathrm{g}^{-1}\right)$ with $11.07 \mathrm{~g}^{-1}$ $\mathrm{L}^{-1}$, respectively. Carotenoid production by strain D3 was higher and statistically different $(p<0.05)$ from the others. These yeasts provided the highest carotenoid production in this study.

Yeast B1 was the best producer of orange pigments with $280 \mu \mathrm{g} \mathrm{L}^{-1}\left(25.33 \mu \mathrm{g} \mathrm{g}^{-1}\right)$ total carotenoid concentration and $11.23 \mathrm{~g} \mathrm{~L}^{-1}$ biomass concentration. Strains A19 and E3 were the best producers of pink carotenoids. They produced $640 \mu \mathrm{g} \mathrm{L}^{-1}(54.07 \mu \mathrm{g}$ $\left.\mathrm{g}^{-1}\right)$, with $11.97 \mathrm{~g} \mathrm{~L}^{-1}$ biomass concentration, and $378.3 \mu \mathrm{g} \mathrm{L}^{-1}\left(9.88 \mu \mathrm{g} \mathrm{g}^{-1}\right)$, with $10.33 \mathrm{~g} \mathrm{~L}^{-1}$ biomass concentration, respectively.

Yeasts with the highest potential for carotenoid production came from the following sources: bark (D3 - Sul-Riograndense Shield), flowers (B12 - Eastern Coast; B1 - Sul-Riograndense Shield), soil (C3 - SulRiograndense Shield), leaves (A19 - Eastern Coast) and fruit (E3 - Sul-Riograndense Shield). Thus, three yeasts with highest potential as carotenoid producers were selected: D3 (yellow), B1 (orange) and A19 (pink). These microorganisms underwent genus and species identification, carotenoid bioproduction kinetics and identification of the major carotenoid producers.

\section{Yeast identification}

After genetic sequencing of the three isolated yeasts, results obtained from GenBank information were compared and led to the following identification: D3 was identified as Sporidiobolus pararoseus (Fig. 1a); B1, as Rhodotorula mucilaginosa (Fig. 1b); and A19, as Pichia fermentans (Fig. 1c). These species showed $100 \%$ of sequence identities in the ITS region and D1/D2 domains with the sequences of reference strains of these species deposited in the GenBank. Among yeasts isolated and selected as carotenoid producers in this study, only Rhodotorula (Libkind et al., 2004; Aksu et al., 2005 and Maldonade et al., 2008) and Sporodiobolus (Cabral et al, 2011; Valduga et al., 2014) have been known as yeasts which produce these pigments. To date, no reports of carotenoid production by Pichia fermentans have been found in the literature.

\section{Partial characterization of substrates}

Partial characterization of yeast extract, malt extract, peptone, crude glycerol, parboiled rice water and sugar cane molasses is described in Table 4. Total nitrogen concentration of parboiled rice water complies with the one found in the literature (Queiroz et al., 2007). Crude glycerol used in this study showed higher carbon concentration $(49.3 \%)$ than that used by Silva et al. (2012), when they studied carotenoid production by Phaffia rhodozyma. Therefore, amounts of nitrogen and carbon found in parboiled rice water and crude glycerol, respectively, are essential for cell growth. Thus, these substrates are potential sources of nutrients in the culture medium.

\section{Bioproduction kinetics of selected yeasts Sporidiobolus pararoseus}

The behavior of $S$. pararoseus can be observed by growth kinetics, $\mathrm{pH}$, TRS concentration and carotenoid production found in YM medium (Fig. 2a). It started after $24 \mathrm{~h}$ of culture $\left(5.69 \mu \mathrm{g} \mathrm{g}^{-1}\right)$ with $50 \%$ TRS $(6.54$ $\mathrm{g} \mathrm{L}^{-1}$ ), which had already been previously consumed, at $\mathrm{pH} 5.39$ and biomass of $3.17 \mathrm{~g} \mathrm{~L}^{-1}$. It increased up to $60 \mathrm{~h}$ and then remained almost constant until 100 $\mathrm{h}$ (TRS depletion). There was an increase in total carotenoids, which reached the maximum of 905.30 $\mu \mathrm{g} \mathrm{L}^{-1}\left(122.82 \mu \mathrm{g} \mathrm{g}^{-1}\right)$ in $168 \mathrm{~h}$, at final $\mathrm{pH} 7.6$ and biomass of $7.32 \mathrm{~g} \mathrm{~L}^{-1}$. Such a $\mathrm{pH}$ change may have happened because a carbon intermediate was excreted by the yeast during growth as acetic acid, alcohol or intermediate of the citric acid cycle, thus causing a decrease in $\mathrm{pH}$. Since this intermediate is subsequently reassimilated, it stimulates strong carotenogenesis and causes an increase in pH (Chociai et al., 2002). Thereafter, the $\mathrm{pH}$ remains constant and indicates the end of the culture.

Carotenoid production in medium A (parboiled rice water and crude glycerol) (Fig. 2b) started after $32 \mathrm{~h}$ $\left(3.82 \mu \mathrm{g} \mathrm{g}^{-1}\right)$ at $\mathrm{pH}$ around 6 and biomass of $4 \mathrm{~g} \mathrm{~L}^{-1}$. It increased after $160 \mathrm{~h}\left(12.06 \mathrm{~g} \mathrm{~L}^{-1}\right)$ and decreased slightly at the end of the cultivation. There was an increase in total carotenoids, whose maximum was $820 \mu \mathrm{g} \mathrm{L}^{-1}\left(68.04 \mu \mathrm{g} \mathrm{g}^{-1}\right)$ after $168 \mathrm{~h}$, at final $\mathrm{pH}$ 8.5.

Carotenoid production in medium B (parboiled rice water and sugar cane molasses) (Fig. 2c) started after $40 \mathrm{~h}\left(1.37 \mu \mathrm{g} \mathrm{g}^{-1}\right)$ with approximately $70 \%$ TRS consumption, at $\mathrm{pH} 5$ and biomass of $4 \mathrm{~g} \mathrm{~L}^{-1}$, which increased up to $168 \mathrm{~h}\left(10.69 \mathrm{~g} \mathrm{~L}^{-1}\right)$. There was an increase in total carotenoids, whose maximum concentration was $710 \mu \mathrm{g} \mathrm{L}^{-1}\left(86.46 \mu \mathrm{g} \mathrm{g}^{-1}\right)$ after168 $\mathrm{h}$ at final $\mathrm{pH}$ 8.2.

Biomass concentration of this yeast achieved lower results in YM medium than in agroindustrial substrates; however, most carotenoid production occurred in YM medium. But in media A and B, volumetric production was promising because it reached about 90 and $78 \%$, respectively, by comparison with YM medium, considering the same processing time (168 h).

\section{Rhodotorula mucilaginosa}

Fig. 3a shows that $R$. mucilaginosa consumed less TRS in YM medium than in other media. However, TRS consumption was similar in medium B for $S$. pararoseus (Fig. 2c) and R. mucilaginosa (Fig $3 c)$. Cultures reached similar maximum biomass concentrations after $168 \mathrm{~h}$, i. e., the agroindustrial medium A reached $12.49 \mathrm{~g} \mathrm{~L}^{-1}$ (Fig. 3b) at final $\mathrm{pH}$ 


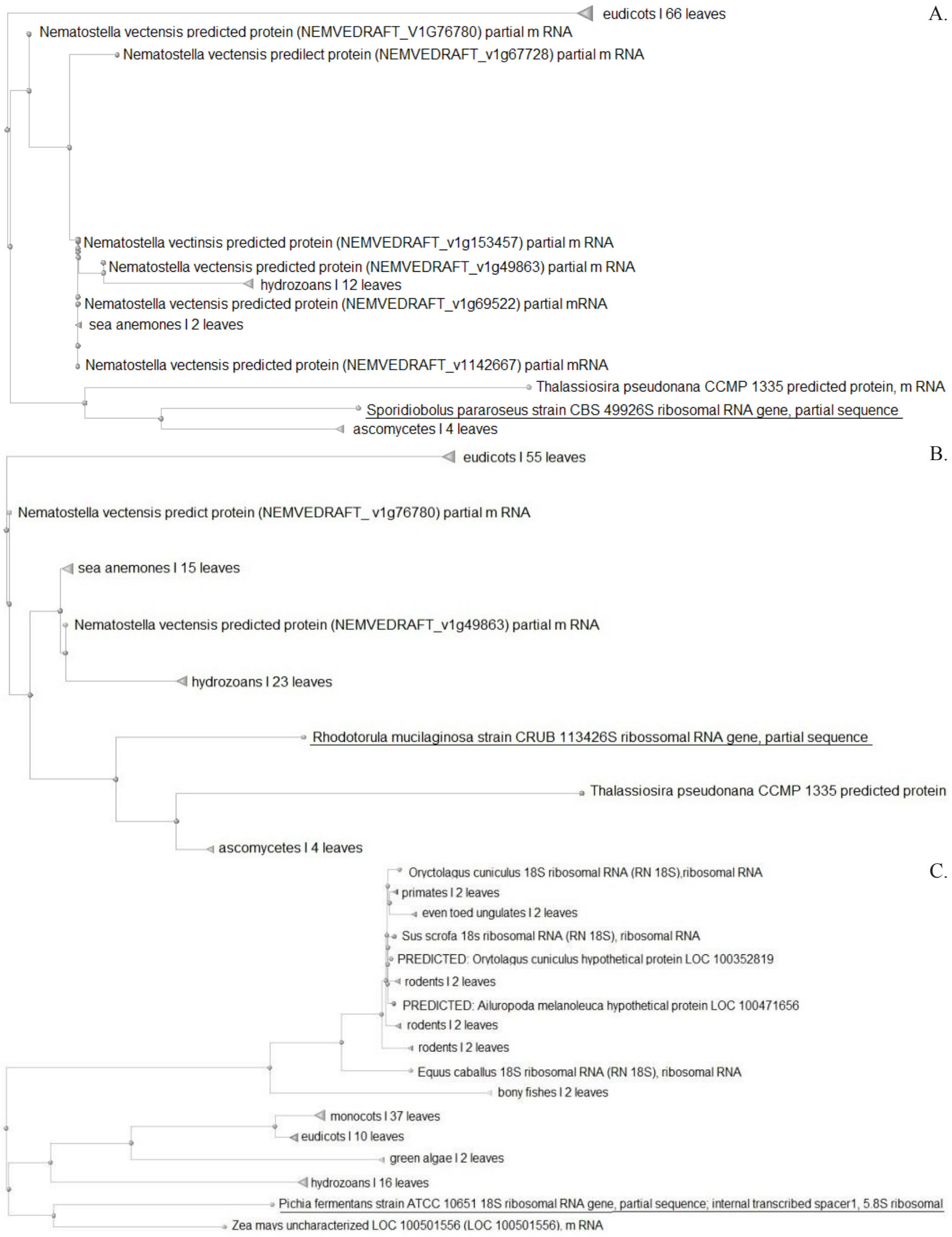

Figure 1. Dendrogram of identification of the yeast for Sporidiobolus pararoseus (a), Rhodotorula mucilaginosa (b) and Pichia fermentans (c). 
Table 4. Partial characterization of substrates found in culture media.

\begin{tabular}{lccc}
\hline \multicolumn{1}{c}{ Substrates } & $\mathbf{\% ~ C ~}$ & \% H & \% N \\
\hline Yeast extract & 38.40 & 5.65 & 10.67 \\
Malt extract & 39.24 & 6.54 & 10.93 \\
Peptone & 43.47 & 6.71 & 14.47 \\
Parboiled rice water & 0.16 & 2.25 & 3.02 \\
Sugar cane molasses & 36.50 & ND* & 0.30 \\
Crude glycerol & 49.30 & ND $^{*}$ & 1.05 \\
\hline \multicolumn{1}{c}{ Standard } & & \\
\hline Sample 1 & 100.24 & 99.55 & 99.90 \\
Sample 2 & 100.29 & 102.83 & 99.81 \\
\% recovery & 100.63 & 106.90 & 100.87 \\
\hline
\end{tabular}

*ND- not determined.
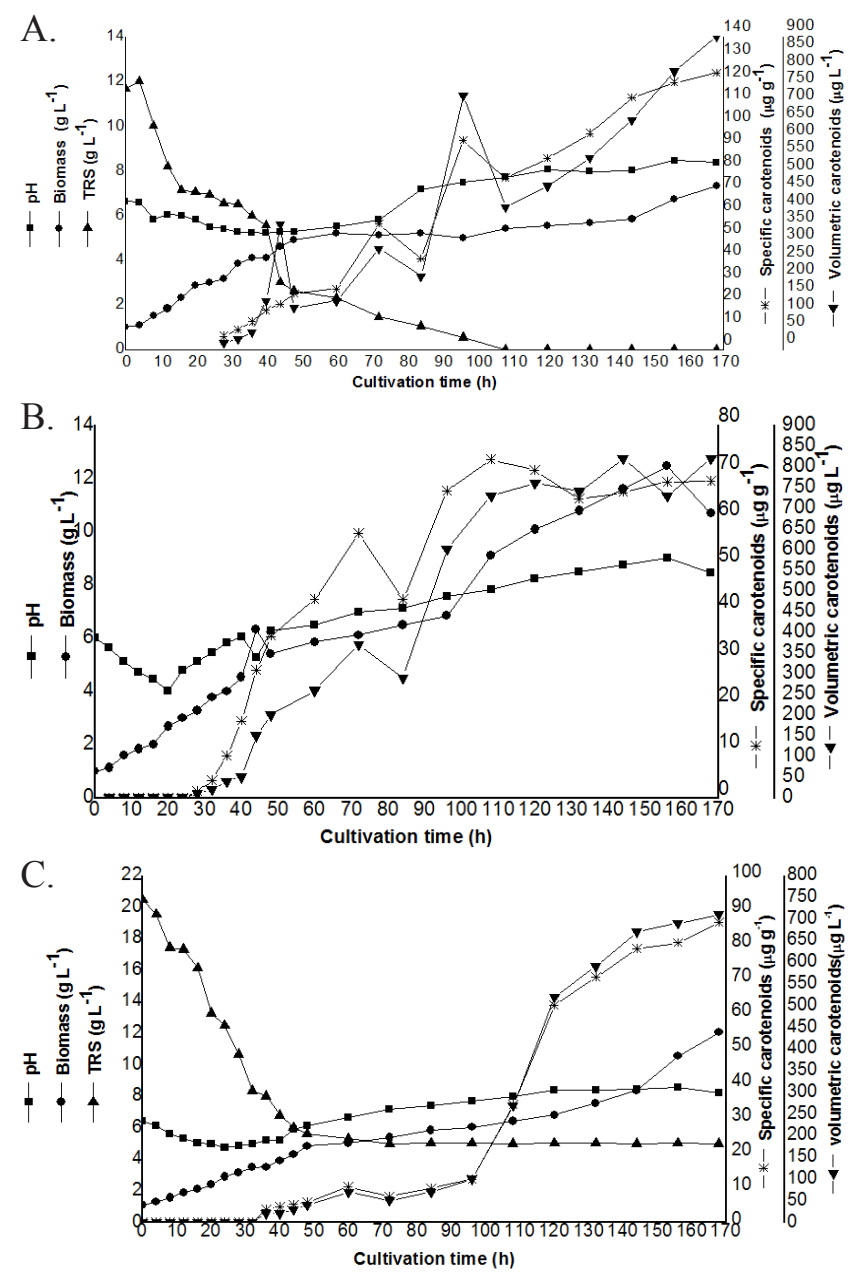

Figure 2. Growth kinetics, consumption of TRS, $\mathrm{pH}$ and production of carotenoids in YM medium (a), medium A parboilized rice water and raw glycerol (b) and medium $\mathrm{B}$ parboilized rice water and sugar cane molasses (c), at $25^{\circ} \mathrm{C}$ and $180 \mathrm{rpm}$ for $168 \mathrm{~h}$ for Sporidiobolus pararoseus.

8.20 whereas medium B attained $12.02 \mathrm{~g} \mathrm{~L}^{-1}$ (Fig. 3c) at final $\mathrm{pH}$ 8.50. YM medium reached $11.18 \mathrm{~g} \mathrm{~L}^{-1}$ (Fig. $3 a)$ at final $\mathrm{pH} 8.10$. The highest carotenoid production began at $40 \mathrm{~h}$ and reached $360 \mu \mathrm{g} \mathrm{L}^{-1}\left(30.16 \mu \mathrm{g} \mathrm{g}^{-1}\right)$ after $168 \mathrm{~h}$ in medium B. Carotenoid production started later $(72 \mathrm{~h})$ and reached $250 \mu \mathrm{g} \mathrm{L}^{-1}(28.06 \mu \mathrm{g}$
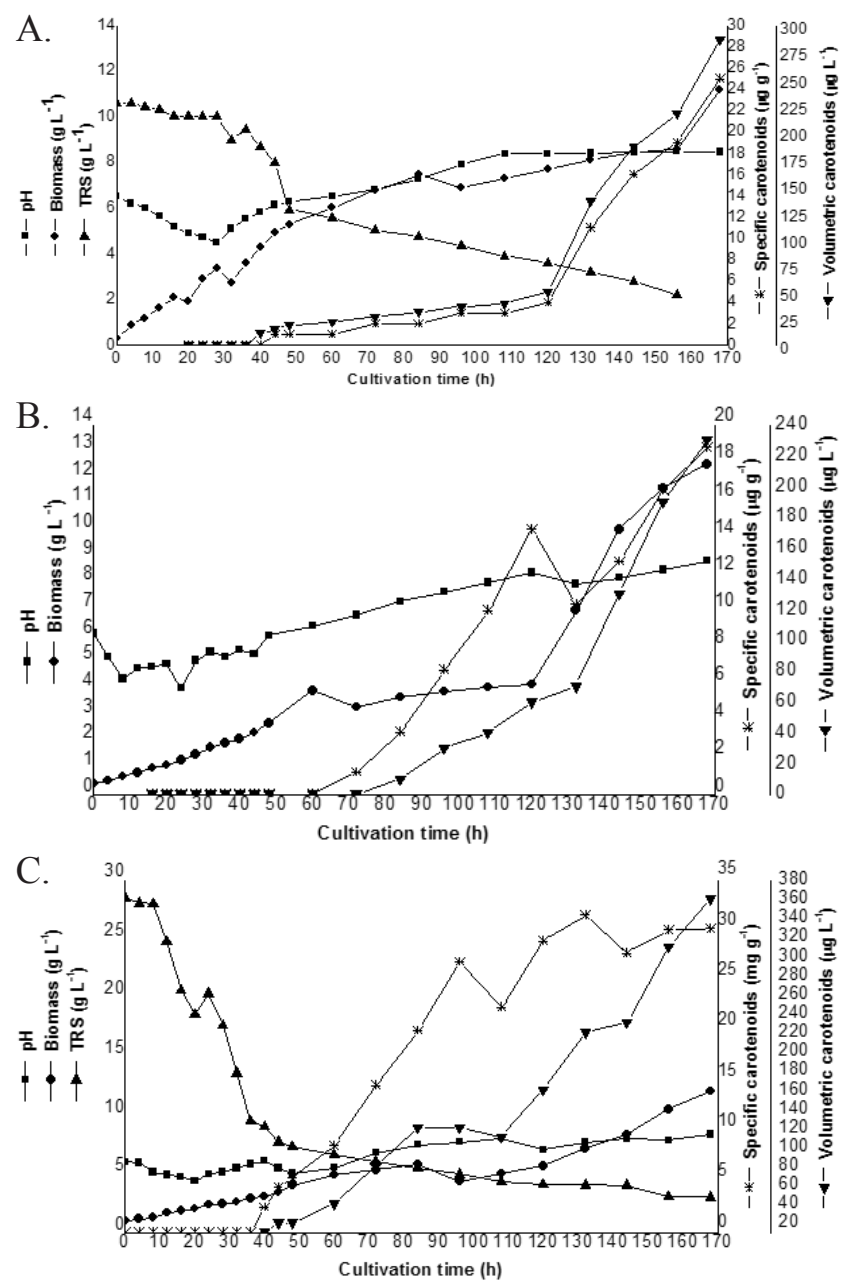

Figure 3. Growth kinetics, consumption of TRS, pH and production of carotenoids in YM medium (a), medium A parboilized rice water and raw glycerol (b) and medium B parboilized rice water and sugar cane molasses (c), at $25^{\circ} \mathrm{C}$ and $180 \mathrm{rpm}$ for $168 \mathrm{~h}$ for Rhodotorula mucilaginosa.

$\left.\mathrm{g}^{-1}\right)$ and $230.00 \mu \mathrm{g} \mathrm{L}^{-1}\left(18.76 \mu \mathrm{g} \mathrm{g}^{-1}\right)$, respectively, in YM medium and medium A after $168 \mathrm{~h}$. Therefore, the medium with sugar cane molasses produced $44 \%$ more than YM medium.

\section{Pichia fermentans}

P. fermentans (Fig. 4a) was able to consume all TRS in YM medium (100 h) and up to $90 \%$ in medium $\mathrm{B}$ by the end of the process (Fig. 4c). The behavior of $\mathrm{pH}$ was similar to the one shown by the other yeasts, $\mathrm{i}$. e., it decreased in the first $50 \mathrm{~h}$ (4.41) and reached 8.36 or 8.15 at the end of the process in YM medium (Fig. 4a). In media $\mathrm{A}$ and $\mathrm{B}$, the $\mathrm{pH}$ decrease occurred until $24 \mathrm{~h}$ and $28 \mathrm{~h}$, respectively, reaching 8.45 and 8.96 after $168 \mathrm{~h}$ in media A and B.

Biomass increased gradually and reached a maximum of $12.32 \mathrm{~g} \mathrm{~L}^{-1}$ in medium B (Fig. 4c), followed by YM medium, where $P$. fermentans produced $11.84 \mathrm{~g} \mathrm{~L}^{-1}$ (Fig. 4a). In medium A, it 

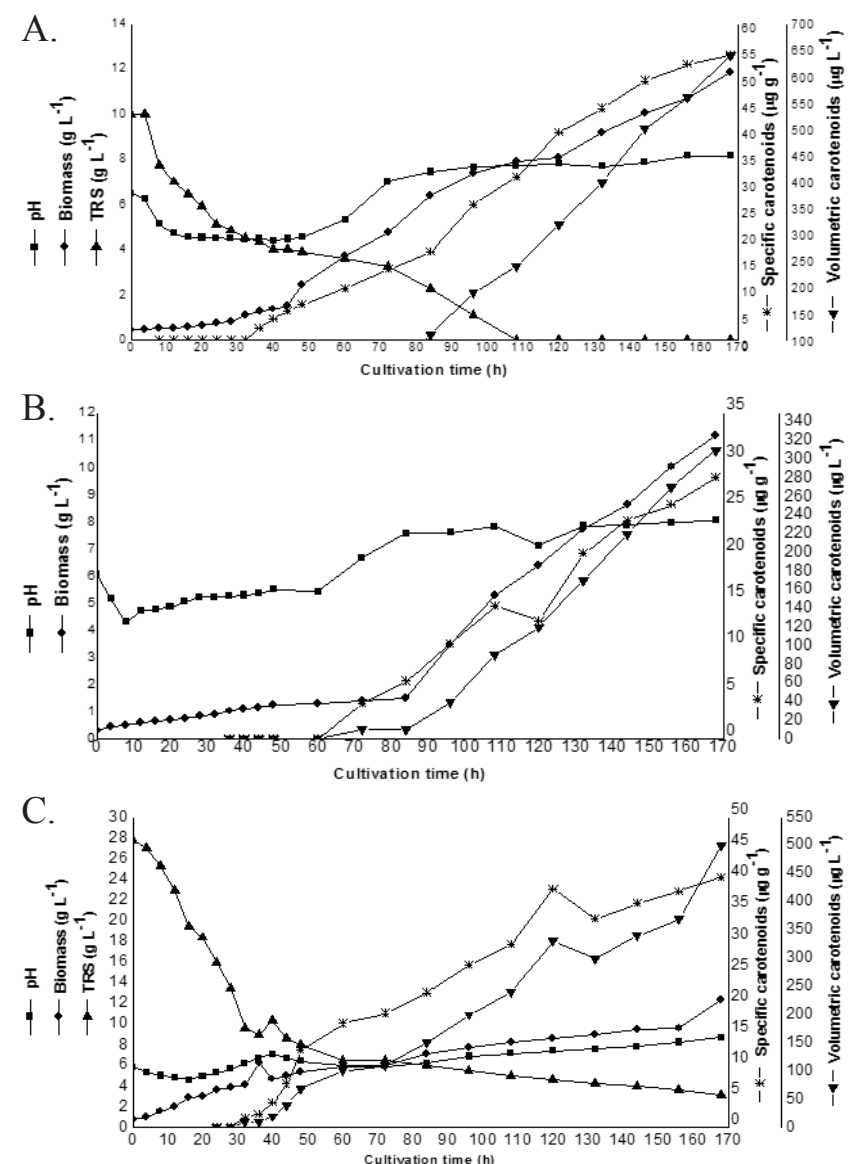

Figure 4. Growth kinetics, consumption of TRS, $\mathrm{pH}$ and production of carotenoids in YM medium (a), medium A parboilized rice water and raw glycerol (b) and medium $\mathrm{B}$ parboilized rice water and sugar cane molasses (c), at $25^{\circ} \mathrm{C}$ and $180 \mathrm{rpm}$ for $168 \mathrm{~h}$ for Pichia fermentans.

produced $9.09 \mathrm{~g} \mathrm{~L}^{-1}$ (Fig. 4b) in $168 \mathrm{~h}$. In YM medium, maximum carotenoid production started after $36 \mathrm{~h}$ and reached $640 \mu \mathrm{g} \mathrm{L}^{-1}\left(54.07 \mu \mathrm{g} \mathrm{g}^{-1}\right)$ after $168 \mathrm{~h}$. In the medium with sugar cane molasses (B), bioproduction started after $32 \mathrm{~h}$, reached $500 \mu \mathrm{g} \mathrm{L}^{-1}\left(40.33 \mu \mathrm{g} \mathrm{g}^{-1}\right)$ and was higher than the one in medium $\mathrm{A}$, whose value was $310 \mu \mathrm{g} \mathrm{L}^{-1}\left(27.83 \mu \mathrm{g} \mathrm{g}^{-1}\right)$ and started after $40 \mathrm{~h}$. The highest carotenoid production occurred in YM medium, but both media $\mathrm{A}$ and $\mathrm{B}$ reached $48 \%$ and $78 \%$, respectively, in the same processing period.

In this study, the agroindustrial medium with sugar cane molasses showed promising results for carotenoid production by the three selected microorganisms. Sugar cane molasses is an excellent culture medium for carotenoid production in microorganisms because its very complex composition contains nutrients, such as nitrogen, potassium, magnesium, manganese and iron, which, individually, can positively influence carotenoid bioproduction. Mevalonate, for instance, is a natural precursor of carotenoids (Valduga et al., 2008).
Some authors have carried out yeast isolation and identification with the objective of carotenoid production. In the agroindustrial media investigated in this study, carotenoid production by $S$. pararoseus (820 $\mu \mathrm{g} \mathrm{L} \mathrm{L}^{-1}$ medium B and $710 \mu \mathrm{g} \mathrm{L}^{-1}$ medium A) was similar or higher than the ones reported in the literature by Maldonade et al. (2007), using $S$. roseus with YM medium (237 $\left.\mu \mathrm{g} \mathrm{L}^{-1}\right)$. Machado and Burkert (2015) reached $521 \mu \mathrm{g} \mathrm{L}^{-1}\left(40 \mathrm{~g} \mathrm{~L}^{-1}\right.$ sugar cane molasses and $6.5 \mathrm{~g} \mathrm{~L}^{-1}$ corn steep liquor) and $780 \mu \mathrm{g} \mathrm{L}^{-1}\left(30 \mathrm{~g} \mathrm{~L}^{-1}\right.$ crude glycerol and $52.9 \mathrm{~g} \mathrm{~L}^{-1}$ corn steep liquor) with the same microorganism of this study. Cabral et al. (2011), with another strain of $S$. pararoseus, using $60 \mathrm{~g} \mathrm{~L}^{-1}$ glucose, $15 \mathrm{~g} \mathrm{~L}^{-1}$ peptone and $15 \mathrm{~g} \mathrm{~L}^{-1}$ malt extract, reached a production of $856 \mu \mathrm{g} \mathrm{L}^{-1}$. With the same strain, but with agroindustrial substrates $(40 \mathrm{~g}$ $\mathrm{L}^{-1}$ glycerol, $40 \mathrm{~g} \mathrm{~L}^{-1}$ corn steep liquor and $20 \mathrm{~g} \mathrm{~L}^{-1}$ parboiled rice water), the carotenoid production was optimized and reached a maximum value of $843 \mu \mathrm{g} \mathrm{L}^{-1}$ (396 $\mathrm{g} \mathrm{L} \mathrm{L}^{-1} \beta$-carotene) (Valduga et al., 2014).

R. mucilaginosa $\left(360 \mu \mathrm{g} \mathrm{L}^{-1}\right.$ with medium $\mathrm{B}$ and $230 \mu \mathrm{g} \mathrm{L}^{-1}$ with medium $\mathrm{A}$ ) isolated in this study had better performance than $R$. mucilaginosa $(100 \mu \mathrm{g}$ $\left.\mathrm{L}^{-1}\right)$ using glucose:glycerol:yeast extract (1:2), $0.5 \%$ Tween 20, $10 \mathrm{mM} \mathrm{H}_{2} \mathrm{O}_{2}$, according to Dhaliwal and Chandra (2015). Aksu et al. (2007), using a complex culture medium $\left(15 \mathrm{~g} \mathrm{~L}^{-1}\right.$ glucose, $2.5 \mathrm{~g} \mathrm{~L}^{-1}$ yeast extract, $2 \mathrm{~g} \mathrm{~L}^{-1}$ malt extract, $1 \mathrm{~g} \mathrm{~L}^{-1}\left(\mathrm{NH}_{4}\right)_{2} \mathrm{SO}_{4}, 1 \mathrm{~g} \mathrm{~L}^{-1}$ $\mathrm{NaH}_{2} \mathrm{PO}_{4}$ and $\left.0.25 \mathrm{~g} \mathrm{~L}^{-1} \mathrm{MgSO}_{4} \cdot 7 \mathrm{H}_{2} \mathrm{O}\right)$ in $R$. glutinis cultivation, reached $125 \mu \mathrm{g} \mathrm{L}^{-1}$. Banzatto et al. (2013) produced $274 \mu \mathrm{g} \mathrm{L}^{-1}$ with $R$. rubra $\left(40 \mathrm{~g} \mathrm{~L}^{-1}\right.$ sugarcane juice, $40 \mathrm{~g} \mathrm{~L}^{-1}$ molasses, $40 \mathrm{~g} \mathrm{~L}^{-1}$ syrup, $2 \mathrm{~g} \mathrm{~L}^{-1}$ urea, $0.5 \mathrm{~g}$ Nitrofos $\mathrm{KL} / \mathrm{L}$ ). However, the performance of the strain of Rhodotorula isolated in this study showed lower carotenoid production ( $\beta$-carotene and torulene) in YM medium than $R$. glutinis $\left(881 \mu \mathrm{g} \mathrm{\textrm {L } ^ { - 1 }}\right)$, $R$. graminis $\left(594 \mu \mathrm{g} \mathrm{L}^{-1}\right)$ and $R$. mucilaginosa (487$590 \mu \mathrm{g} \mathrm{L}^{-1}$ ) (Maldonade et al., 2007). Zeni et al. (2011) isolated three yeasts, among other microorganisms, with great potential to produce red carotenoids, with total carotenoid production of $707-818 \mu \mathrm{g} \mathrm{L}^{-1}$ in a culture medium composed of $40 \mathrm{~g} \mathrm{~L}^{-1}$ glucose, $14 \mathrm{~g} \mathrm{~L}^{-1}$ bacto peptone and $10 \mathrm{~g} \mathrm{~L}^{-1}$ malt extract.

P. fermentans $\left(500 \mu \mathrm{g} \mathrm{L}^{-1}\right.$ or $40.33 \mu \mathrm{g} \mathrm{g}^{-1}$ medium B and $310 \mu \mathrm{g} \mathrm{L}^{-1}$ or $27.83 \mu \mathrm{g} \mathrm{g}^{-1}$ medium $\mathrm{A}$ ), a new isolated yeast, produced 10 -fold the amount of carotenoids in agroindustrial medium $\left(40.33 \mu \mathrm{g} \mathrm{g}^{-1}\right)$, by comparison with genetically modified yeast $P$. pastoris $\left(4 \mu \mathrm{g} \mathrm{g}^{-1}\right)$, according to Araya-Garay et al. (2012).

Brazil has a broad microorganism diversity which has been inadequately investigated. However, major development in production processes is needed before these pigments can reach the consumer market (Mezzomo and Ferreira, 2016). Native microorganisms screened in this study showed that their potential is similar to or higher than the one of those described 
in the literature as microbial sources for carotenoid production in submerse cultivation. Nevertheless, the performance of these yeasts can be improved by optimizing production conditions.

Table 5 shows kinetic parameters of the yeasts $S$. pararoseus, $R$. mucilaginosa and $P$. fermentans in three culture media. $\mu_{\text {máx }}$ was similar or higher in media with alternative substrates than in YM medium for all yeasts. S. pararoseus (YM medium and medium B) and $P$. fermentans (medium A) reached $0.28 \mathrm{~h}^{-1}$, while $R$. mucilaginosa reached $0.24 \mathrm{~h}^{-1}$ (medium B). Similar behavior was observed in biomass productivity $\left(\mathrm{P}_{\mathrm{x}}\right)$, which showed little variation in the conditions under study (0.04-0.07 $\left.\mathrm{g} \mathrm{L}^{-1} \mathrm{~h}^{-1}\right)$. Maximum $\mathrm{P}_{\mathrm{x}}$ of $0.07 \mathrm{~g}$ $\mathrm{L}^{-1} \mathrm{~h}^{-1}$ was found for $S$. pararoseus (medium B), $P$. fermentans (YM medium and medium B) and $R$. mucilaginous (medium A).

Total carotenoid productivity $\left(\mathrm{P}_{\mathrm{c}}\right)$ for $S$. pararoseus was higher in YM medium $\left(0.70 \mu \mathrm{g} \mathrm{L}^{-1} \mathrm{~h}^{-1}\right)$, but with sugar cane molasses (medium B, $0.62 \mu \mathrm{g} \mathrm{L}^{-1} \mathrm{~h}^{-1}$ ), it reached $88 \%$ of this productivity. $P$. fermentans

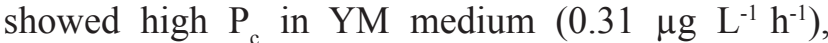
whereas that of $R$. mucilaginosa was high in medium A $\left(0.16 \mu \mathrm{g} \mathrm{L}^{-1} \mathrm{~h}^{-1}\right)$.

Regarding conversion factors, $\mathrm{Y}_{\mathrm{X} / \mathrm{S}}$ was high in YM medium for $P$. fermentans $\left(1.13 \mathrm{~g} \mathrm{~g} \mathrm{~g}^{-1}\right)$ and $R$. mucilaginosa $\left(1.30 \mathrm{~g} \mathrm{~g}^{-1}\right)$. However, $S$. pararoseus $(0.70$ $\mathrm{g} \mathrm{g}^{-1}$ ) showed high conversion in medium A while $\mathrm{Y}_{\mathrm{P} / \mathrm{S}}$ was higher in YM medium, considering all yeasts. $\mathrm{Y}_{\mathrm{P} / \mathrm{X}}$ was higher in YM medium for $S$. pararoseus (19.57 $\mu \mathrm{g} \mathrm{g}^{-1}$ ) and $P$. fermentans $\left(4.75 \mu \mathrm{g} \mathrm{g}^{-1}\right)$, even though $R$. mucilaginosa showed higher values in medium B $\left(2.74 \mu \mathrm{g} \mathrm{g}^{-1}\right)$.

Table 5. Kinetic parameters of $S$. pararoseus, $P$. fermentans and R. mucilaginosa.

\begin{tabular}{|c|c|c|c|c|}
\hline & $\begin{array}{c}\text { Kinetic } \\
\text { parameters }\end{array}$ & $\mathbf{Y M}$ & $\begin{array}{c}\text { Medium } \\
\mathrm{A}^{*} \\
\end{array}$ & $\begin{array}{c}\text { Medium } \\
\text { B* }\end{array}$ \\
\hline \multirow{6}{*}{ S. pararoseus } & $\mu_{\max }\left(h^{-1}\right)$ & 0.28 & 0.15 & 0.28 \\
\hline & $\mathrm{YP}_{\mathrm{P} / \mathrm{S}}\left(\mu \mathrm{g} \mathrm{g}^{-1}\right)$ & 10.30 & 5.60 & ND** \\
\hline & $\mathrm{YX}_{\mathrm{X} / \mathrm{S}}\left(\mathrm{g} \mathrm{g}^{-1}\right)$ & 0.53 & 0.70 & ND** \\
\hline & $\mathrm{Y}_{\mathrm{P} / \mathrm{X}}\left(\mu \mathrm{g} \mathrm{g}^{-1}\right)$ & 19.57 & 7.90 & 10.94 \\
\hline & $P_{X}\left(g^{-1} h^{-1}\right)$ & 0.04 & 0.06 & 0.07 \\
\hline & $\mathrm{P}_{\mathrm{C}}\left(\mu \mathrm{g} \mathrm{L}^{-1} \mathrm{~h}^{-1}\right)$ & 0.70 & 0.50 & 0.62 \\
\hline \multirow{6}{*}{ P. fermentans } & $\mu_{\max }\left(h^{-1}\right)$ & 0.17 & 0.28 & 0.20 \\
\hline & $\mathrm{Y}_{\mathrm{P} / \mathrm{S}}\left(\mu \mathrm{g} \mathrm{g}^{-1}\right)$ & 5.40 & 1.35 & ND** \\
\hline & $Y_{X / S}\left(\mathrm{~g} \mathrm{~g}^{-1}\right)$ & 1.13 & 0.43 & ND** \\
\hline & $Y_{P / X}\left(\mu g^{-1}\right)$ & 4.75 & 3.16 & 3.50 \\
\hline & $P_{X}\left(g^{-1} h^{-1}\right)$ & 0.07 & 0.05 & 0.07 \\
\hline & $P_{C}\left(\mu g^{-1} h^{-1}\right)$ & 0.31 & 0.05 & 0.07 \\
\hline \multirow{6}{*}{ R. mucilaginosa } & $\mu_{\max }\left(h^{-1}\right)$ & 0.16 & 0.14 & 0.24 \\
\hline & $\mathrm{Y}_{\mathrm{P} / \mathrm{S}}\left(\mu \mathrm{g} \mathrm{g}^{-1}\right)$ & 3.36 & 0.94 & ND** \\
\hline & $\mathrm{YX} / \mathrm{s}\left(\mathrm{g} \mathrm{g}^{-1}\right)$ & 1.30 & 0.60 & $\mathrm{ND}^{* *}$ \\
\hline & $\mathrm{Y}_{\mathrm{P} / \mathrm{X}}\left(\mu \mathrm{g} \mathrm{g}^{-1}\right)$ & 2.60 & 1.55 & 2.74 \\
\hline & $P_{X}\left(g^{-1} h^{-1}\right)$ & 0.06 & 0.07 & 0.06 \\
\hline & $P_{C}\left(\mu g^{-1} h^{-1}\right)$ & 0.14 & 0.10 & 0.16 \\
\hline
\end{tabular}

*Medium A (parboiled rice water and glycerol) and medium B (parboiled rice water and sugar cane molasses).

**ND- not determined.
Parameters under evaluation, such as $\mu_{\text {máx }}, P_{x}$ and $\mathrm{P}$, obtained promising results with the use of agroindustrial substrates (medium A and medium B) for $S$. pararoseus, $R$. mucilaginosa and $P$. fermentans, while conversion factors showed different performances.

\section{Identification of carotenoids produced by selected yeasts}

Three carotenoids produced by the selected yeasts were identified. $S$. pararoseus and $P$. fermentans produced $\beta$-carotene and $\beta$-cryptoxanthin, respectively. However, only $\beta$-cryptoxanthin was identified as having been produced by $R$. mucilaginosa. Two peaks were not identified at elution times of 21.0 and 27.7 min. Maldonade et al. $(2007,2008)$ also reported $\beta$-carotene in $R$. mucilaginosa, $R$. graminis, $R$. glutinis, $R$. minuta and Sporobolomyces yeasts as one of the major carotenoids. However, except in $R$. minuta, these authors also found torulene at high concentrations.

This study offers an alternative for carotenoid production, i. e., $\beta$-carotene and $\beta$-cryptoxanthin, by a new yeast $(P$. fermentans $)$, since, in the literature, this yeast is only described as producer of this biocompound by genetically modified strains (ArayaGaray et al., 2012). In addition, it demonstrated the potential of the biodiversity found in southern Brazil.

\section{CONCLUSION}

This study isolated 64 wild yeasts from environmental samples collected in ecosystems located in southern Brazil (the Sul-Riograndense Shield and the Eastern Coast). They are good sources of microbial diversity to obtain yeasts for carotenoid production with the use of alternative agroindustrial substrates so as to minimize future costs of biopigment production, add value to these byproducts and mitigate environmental impact. $S$. pararoseus is the most promising yeast for carotenoid production, since it produced $\beta$-cryptoxanthin and $\beta$-carotene, reaching $820 \mu \mathrm{g} \mathrm{L}^{-1}$ in medium B (parboiled rice water and sugar cane molasses) and $710 \mu \mathrm{g} \mathrm{L}^{-1}$ in medium A (parboiled rice water and crude glycerol). These values were 90 and $78 \%$, respectively, of the production obtained in YM medium. The new yeast $P$. fermentans produced the same carotenoids, reaching $48 \%$ (medium A) and $78 \%$ (medium B), by comparison with the production in YM medium. The carotenoid production with $R$. mucilaginosa was lower than the one obtained with the other yeast, with $360 \mu \mathrm{g} \mathrm{L}^{-1}$ (medium B, 44\% above the production in YM medium) and $230 \mu \mathrm{g} \mathrm{L}^{-1}$ (medium A, 92\% above the production in YM medium). Parameters under evaluation, such as $\mu_{\text {máx }}, \mathrm{P}_{\mathrm{x}}$ and $\mathrm{P}_{\mathrm{c} \text {, }}$ gave promising results with the use of agroindustrial substrates (medium A and medium B), while 
conversion factors showed different performances. Therefore, the use of agroindustrial residues in yeast cultivation aiming at carotenoid production is more efficient, more interesting and cheaper than complex media, such as YM.

\section{ACKNOWLEDGEMENTS}

The authors would like to thank CAPES (Brazilian Agency for Improvement of Graduate Personnel) and $\mathrm{CNPq}$ (National Council of Science and Technological Development) for the financial support.

\section{REFERENCES}

Ahmed, F., Fanning, K., Netzel, M., Tunner, W., Li, Y. and Schenk, P.M., Profiling of carotenoids and antioxidant capacity of microalgae from subtropical coastal and brackish waters. Food Chemistry, 165, 300-306 (2014). https://doi.org/10.1016/j. foodchem.2014.05.107

Aksu, Z. and Eren, A.T., Production of carotenoids by isolated yeast of Rhodotorula glutinis. Bioscience Engineering Journal, 35,107-113 (2007). https:// doi.org/10.1016/j.bej.2007.01.004

André Toselo Tropical Culture Collection: at http:// www.fat.org.br

Association of Official Analytical Chemists. Official Methods of Analysis, 17 $17^{\text {th }}$ ed. Association of Official Analytical Chemists, Gaithersburg, MD (2000).

Araya-Garay, J.M., Feijoo-Siota, L., Rosa-dos-Santos, F., Veiga-Crespo, P. and Villa, T.G., Construction of new Pichia pastoris $X-33$ strains for production of lycopene and $\beta$-carotene. Applied Microbiology and Biotechnology, 93, 2483-2492 (2012). https:// doi.org/10.1007/s00253-011-3764-7

Bailey, J.E. and Ollis, D.F., In biochemical engineering fundamentals, second ed. McGraw-Hill, New York (1986).

Banzatto, D., Freitas, L.A. and Mutton, M.J.R., Carotenoid production by Rhodotorula rubra cultivated in sugarcane juice, molasses and syrup. Food Science and Technology, 33, 1418 (2013). https://doi.org/10.1590/S010120612013000500003

BLAST: at http://www.ncbi.nlm.nih.gov. National Institute of Health, NCBI Basic Local Alignment Search Tool.http://www.ncbi.nlm.nih.gov

Cabral, M.M.S., Cence, K., Zeni, J., Tsai, S.M., Durrer, A., Foltran, L.L., Toniazzo, G., Valduga, E. and Treichel, H., Carotenoids production from a newly isolated Sporidiobolus pararoseus strain by submerged fermentation. European Food Research \& Technology, 233, 159-166 (2011). https://doi. org/10.1007/s00217-011-1510-0
Chociai, M.B., Machado, I.M.P., Fontana, J.D., Chociai, J.G., Bussato, S.B. and Bonfim, T.M.B., Cultivation of Phaffia rhodozyma (Xanthophyllomyces dendrorhous) yeast in discontinuous system to obtain astaxanthin. Revista Brasileira de Ciências Farmacêuticas, 38, 457-462 (2012)

Cipolatti, E., Bulsing, B., Sá, C.S., Burkert, C.A.V., Furlong, E.B. and Burkert, J.F.M., Carotenoids from Phaffia rhodozyma: Antioxidant activity and stability of extracts. African Journal of Biotechnology, 14, 1982-1988 (2015). https://doi. org/10.5897/AJB2015.14682

Daniel H.-M., Vrancken G., Takrama J. F., Camu N., De Vos P., De Vuyst L. Yeast diversity of Ghanaian cocoa bean heap fermentations FEMS Yeast Research, 9, 774-783 (2009). https://doi. org/10.1111/j.1567-1364.2009.00520.x

Domínguez-Bocanegra, A.R. and Torres-Muñoz, J.A., Astaxanthin hyperproduction by Phaffia rhodozyma (now Xanthophyllomyces dendrorhous) with raw coconut milk as sole source of energy. Applied Microbiology and Biotechnology, 66, 249-252 (2004). https://doi.org/10.1007/s00253004-1686-3

Dhaliwal, M.K. and Chandra, N., Optimization of carotenoids production by Rhodotorula mucilaginosa. International Journal of Pharmaceutical Science and Research, 6, 11611165 (2015).

El-Rhman, El-Banna, A.A., Abd El-Razek, A.M. and El-Mahdy, A.R., Isolation, identification and screening of carotenoid-Producing strains of Rhodotorula glutinis. Food and Nutrition Sciences, 3, 627-633 (2012). https://doi.org/10.4236/ fns. 2012.35086

Fonseca, R.A.S., Rafael, R.S., Kalil, S.J., Burkert, C.A.V., Burkert. and J.F.M., Different cell disruption methods for astaxanthin recovery by Phaffia rhodozyma. African Journal of Biotechnology, 10, 1165-1171 (2011).

Fusco, D., Colloca, G., Lo Monaco, M.R. and Cesari, M., Effects of antioxidant supplementation on the aging process. Journal of clinical Intervention Aging, 2, 377-387 (2007).

Gadanho, M. and Sampaio, J.P., Polyphasic taxonomy of the basidiomycetous yeast genus Rhodotorula: Rh. glutinis sensu stricto and Rh. dairenensis comb. nov. FEMS Yeast Research, 2, 47-58 (2002).

Jehlička, J., Edwards, H.G.M. and Oren, A., Bacterioruberin and salinixanthin carotenoids of extremely halophilic Archaea and Bacteria: A Raman spectroscopic study. Spectrochimica Acta Part A: Molecular and Biomolecular Spectroscopy, 106, 99-103 (2013). https://doi.org/10.1016/j. saa.2012.12.081 
Kuo, F.S., Chien, Y.H. and Chen, C.J., Effects of light sources on growth and carotenoid content of photosynthetic bacteria Rhodopseudomonas palustris. Bioresource Technology, 113, 315-318 (2012). https://doi.org/10.1016/j. biortech.2012.01.087

Kurtzman C.P, Robnett, C.J. Identification and phylogeny of ascomycetous yeasts from analysis of nuclear large subunit (26S) ribosomal DNA partial sequences. Antonie Van Leeuwenhoek, 73, 331-371 (1998). https://doi.org/10.1023/A:1001761008817

Kusdiyantini, E., Gaudin, P., Goma, G. and Blanc, P.J., Growth kinetics and astaxanthin production of Phaffia rhodozyma on glycerol as a carbon source during batch fermentation. Biotechnology Letters, 20, 929-934 (1998). https://doi. org/10.1023/A:1005345224510

Lachance, M.A., Bowles, J.M., Starmer, W.T. and Barker, J.S., Kodamaea kakaduensis and Candida tolerans, two new ascomycetous yeast species from Australian Hibiscus flowers. Canadian Journal of Microbiology, 45, 172-177 (1999). https://doi. org/10.1139/w98-225

Libkind, D., Brizzio, S., Ruffini, A., Gadanho, M., Broock, M. and Sampaio, J.P., Molecular characterization of carotenogenic yeasts from aquatic environments in Patagonia, Argentina. Antonie Van Leeuwenhoek, 84, 313-322 (2003). https://doi.org/10.1023/A:1026058116545

Liu, J., Huang, J., Jiang, Y. and Chen, F., Molassesbased growth and production of oil and astaxanthin by Chlorella zofingiensis. Bioresource Technology, 107, 393-398 (2012). https://doi.org/10.1016/j. biortech.2011.12.047

Ma, L. and Lin, X.M., Effects of lutein and zeaxanthin on aspects of eye health. Journal of the Science of Food and Agriculture, 90, 2-12 (2010). https://doi. org/10.1002/jsfa.3785

Machado, F.R.S., Trevisol, T.C., Boschetto, D., Burkert, J.F.M., Ferreira, S.R.S., Oliveira, J.V. and Burkert, C.A.V., Technological process for cell disruption, extraction and encapsulation of astaxanthin from Haematococcus pluvialis. Journal of Biotechnology, 218,108-114 (2016). https://doi. org/10.1016/j.jbiotec.2015.12.004

Machado, W.R.C. and Burkert, J.F.M., Optimization of agroindustrial medium for the production of carotenoids by wild yeast Sporidiobolus pararoseus. African Journal of Microbiology Research, 9, 209-219 (2015). https://doi. org/10.5897/AJMR2014.7096

Maldonade, I.R., Scamparini, A.R.P. and RodriguezAmaya, D.B. Selection and characterization of carotenoids- producing yeasts from Campinas region, Brazil. Brazilian Journal of Microbiology, 38, 65-70 (2007). https://doi.org/10.1590/S151783822007000100014
Maldonade, I.R., Rodriguez-amaya, D.B. and Scamparini, R.P., Carotenoids of yeast isolated from the Brazilian ecosystem. Food Chemistry, 170, 145-150 (2008). https://doi.org/10.1016/j. foodchem.2007.07.075

Maldonade, I.R., Rodriguez-Amaya, D.B., Scamparini, A.R.P. Statistical optimisation of cell growth and carotenoid production by Rhodotorula mucilaginosa. Brazilian Journal of Microbiology, 43,109-115 (2012). https://doi.org/10.1590/S151783822012000100012

Manimala, M.R.A., Murugesan, R. Studies on carotenoid pigment production by yeast Rhodotorula mucilaginosa using cheap materials of agro-industrial origin. The Pharma Innovation, 6, 80 (2017).

Manowattana, A., Techapun, C., Watanabe, M., \& Chaiyaso, T.. Bioconversion of biodiesel-derived crude glycerol into lipids and carotenoids by an oleaginous red yeast Sporidiobolus pararoseus KM281507 in an airlift bioreactor. Journal of bioscience and bioengineering, 125, 59-66 (2018)

Marinova. D. and Ribarova, F., HPLC determination of carotenoids in Bulgarian berries. Journal of Food Composition and Analysis, 20, 370-374 (2007). https://doi.org/10.1016/j.jfca.2006.09.007

Mezzomo, N. andFerreira, S., Carotenoids functionality, sources, and processing by supercritical technology: a review. Journal of Chemistry, 2016, 1-16 (2016). http://dx.doi.org/10.1155/2016/3164312

Michelon, M., Borba, T.M., Rafael, R.S., Burkert, C.A.V. and Burkert, J.F.M., Extraction of carotenoids from Phaffia rhodozyma: a comparison between different techniques of cell disruption. Food Science and Biotechnology, 21, 1-8 (2012). https://doi.org/10.1007/s10068-012-0001-9

Miller, G.L., Use of dinitrosalicylic acid reagent for determination of reducing sugar. Analytical Chemistry, 31, 426-428 (1959). https://doi. org/10.1021/ac60147a030

Preetha, A., Ajaikumar, B.K., Chitra, S., Kuzhuvelil, B.H., Sheeja, T.T., Oiki, S.L., Bokyung, S. and Bharat, B.A., Cancer is a preventable disease that requires major lifestyle changes. Pharmaceutical Research, 25, 2097-2116 (2008). https://doi. org/10.1007/s11095-008-9661-9

Pollmann, H., Breitenbach, J., Wolff, H., Bode, H. B., Sandmann, G. Combinatorial biosynthesis of novel multi-hydroxy carotenoids in the red yeast Xanthophyllomyces dendrorhous. Journal of Fungi, 3, 9 (2017). https://doi.org/10.3390/jof3010009

Queiroz, M.I., Lopes, E.J., Zepka, L.Q., Bastos, R.G. and Goldbeck, R., The kinetics of the removal of nitrogen and organic matter from parboiled rice effluent by cyanobacteria in a stirred batch reactor. Bioresource Technology, 98, 2163-2169 (2007). https://doi.org/10.1016/j.biortech.2006.08.034 
Rao, A.V. and Rao, L.G. Carotenoids and human health. Pharmaceutical Research, 55, 207-216 (2007). https://doi.org/10.1016/j.phrs.2007.01.012

Rios, D.A.S., Borba, T.M., Kalil, S.J. and Burkert, J.F.M., Use of rice parboiling wastewater in maximization of carotenoids bioproduction by Phaffia rhodozyma. Ciência e Agrotecnologia, 39, 401-410 (2015). https://doi.org/10.1590/S1413-70542015000400011

Rodriguez-Amaya, D.B., Kimura, M., Godoy, H.T. and Amaya-Farfan, J., Update Brazilian database on food carotenoids: Factors affecting carotenoid composition. Journal of Food Composition and Analysis, 21, 445-463 (2008). https://doi. org/10.1016/j.jfca.2008.04.001

Silva, C.M., Borba, T.M., Burkert, C.A.V. and Burkert, J.F.M., Carotenoid production by Phaffiarhodozyma using raw glycerol as an additional carbon source. International Journal of Food Engineering, 8, (2012). http://dx.dor.org/ 10.1515/1556-3758.2843

Silva, C.M., Borba, T.M., Kalil, S.J. and Burkert, J.F.M., Raw glycerol and parboiled rice effluent for carotenoid production: Effect of the composition of culture medium and initial $\mathrm{pH}$. Food Technology and Biotechnology, 54, 489-496 (2016).

Tuli, H. S., Chaudhary, P., Beniwal, V., and Sharma, A. K., Microbial pigments as natural color sources: current trends and future perspectives. Journal of Food Science and Technology, 52, 4669-4678 (2015). https://doi.org/10.1007/s13197-014-1601-6
Valduga, E., Valério, A., Treichel, H., Di Luccio, M. and Júnior, A., Study of the bio-production of carotenoids by Sporidiobolus salmonicolor (CBS 2636) using pre-treated agro-industrial substrates. Journal of Chemical Technology and Biotechnology, 83, 1267-1274 (2008). https://doi. org/10.1002/jctb. 1940

Valduga, E., Ribeiro, A. H. R., Cence, K., Colet, R., Tiggemann, L., Zeni, J., Toniazzo, G. Carotenoids production from a newly isolated Sporidiobolus pararoseus strain using agroindustrial substrates. Biocatalysis and Agricultural Biotechnology, 3, 207-213 (2014). https://doi.org/10.1016/j. bcab.2013.10.001

White, T.J., Bruns, T.D. and Lee, S.B., Amplification and direct sequencing of fungal ribosomal RNA genes for phylogenetics, in: M. Innis, D. Gelfand, J. Sninsky and T. White (Eds.), PCR Protocols: A Guide to Methods and Applications, Academic Press, Florida, pp. 281-304 (1990).

Wei N, Xu Q, Z N. Extraction and Identification of Carotenoids in Sporobolomyces pararoseus. Food Science, 19, 133-137 (2014).

Zeni, J., Colet, R., Cence, K., Tiggemann, L., Toniazzo, G., Cansian, R.L., Di Luccio, M., Oliveira, D. and Valduga, E., Screening of microorganisms for production of carotenoids. CyTA- Journal of Food, 9, 160-166 (2011). https://doi.org/10.1080/194763 37.2010 .499570 
